\title{
M1 ipRGCs Influence Visual Function through Retrograde Signaling in the Retina
}

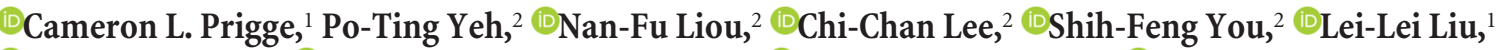 \\ ๑David S. McNeill, ${ }^{3}{ }^{\circledR}$ Kylie S. Chew, ${ }^{3}$ Samer Hattar, ${ }^{3}{ }^{\circledR}$ Shih-Kuo Chen, ${ }^{2,4}$ and ${ }^{\circledR D a o-Q i}$ Zhang ${ }^{1}$ \\ ${ }^{1}$ Eye Research Institute, Oakland University, Rochester, Michigan 48309, 2Department of Life Science, National Taiwan University, Taipei, Taiwan 10617, \\ ${ }^{3}$ Department of Biology, Johns Hopkins University, Baltimore, Maryland 21218, and ${ }^{4}$ Genome and Systems Biology Degree Program, National Taiwan \\ University and Academia Sinica, Taipei, Taiwan 10617
}

Melanopsin-expressing intrinsically photosensitive retinal ganglion cells (ipRGCs, with five subtypes named M1-M5) are a unique subclass of RGCs with axons that project directly to many brain nuclei involved in non-image-forming functions such as circadian photoentrainment and the pupillary light reflex. Recent evidence suggests that melanopsin-based signals also influence image-forming visual function, including light adaptation, but the mechanisms involved are unclear. Intriguingly, a small population of M1 ipRGCs have intraretinal axon collaterals that project toward the outer retina. Using genetic mouse models, we provide three lines of evidence showing that these axon collaterals make connections with upstream dopaminergic amacrine cells (DACs): (1) ipRGC signaling to DACs is blocked by tetrodotoxin both in vitro and in vivo, indicating that ipRGC-to-DAC transmission requires voltage-gated $\mathrm{Na}^{+}$channels; (2) this transmission is partly dependent on $\mathrm{N}$-type $\mathrm{Ca}^{2+}$ channels, which are possibly expressed in the axon collateral terminals of ipRGCs; and (3) fluorescence microscopy reveals that ipRGC axon collaterals make putative presynaptic contact with DACs. We further demonstrate that elimination of M1 ipRGCs attenuates light adaptation, as evidenced by an impaired electroretinogram b-wave from cones, whereas a dopamine receptor agonist can potentiate the cone-driven b-wave of retinas lacking M1 ipRGCs. Together, the results strongly suggest that ipRGCs transmit luminance signals retrogradely to the outer retina through the dopaminergic system and in turn influence retinal light adaptation.

Key words: amacrine cell; dopamine; ganglion cell; melanopsin; retina; vision

\section{Significance Statement}

Melanopsin-expressing intrinsically photosensitive retinal ganglion cells (ipRGCs) comprise a third class of retinal photoreceptors that are known to mediate physiological responses such as circadian photoentrainment. However, investigation into whether and how ipRGCs contribute to vision has just begun. Here, we provide convergent anatomical and physiological evidence that axon collaterals of ipRGCs constitute a centrifugal pathway to DACs, conveying melanopsin-based signals from the innermost retina to the outer retina. We further demonstrate that retrograde signals likely influence visual processing because elimination of axon collateral-bearing ipRGCs impairs light adaptation by limiting dopamine-dependent facilitation of the cone pathway. Our findings strongly support the hypothesis that retrograde melanopsin-based signaling influences visual function locally within the retina, a notion that refutes the dogma that RGCs only provide physiological signals to the brain.

\section{Introduction}

The visual system operates over a large range of light levels as lighting conditions change across 10 orders of magnitude from

Received Sept. 17, 2015; revised May 25, 2016; accepted May 26, 2016.

Author contributions: C.L.P., S.-K.C., and D.-Q.Z. designed research; C.L.P., P.-T.Y., N.-F.L., C.-C.L., S.-F.Y., L.-L.L., S.-K.C., and D.-Q.Z. performed research; D.S.M., K.S.C., and S.H. contributed unpublished reagents/analytic tools; C.L.P., P.-T.Y., N.-F.L., C.-C.L., S.-F.Y., and S.-K.C. analyzed data; C.L.P., S.-K.C., and D.-Q.Z. wrote the paper.

This work was supported by the National Institutes of Health (Grant R01 EY022640 to D.-Q.Z.), Oakland University Provost's Graduate Student Research Awards (C.L.P.), and the Taiwan Ministry of Science and Technology (Grant MOST-103-2321-B-002-045 to S.-K.C.). We thank Drs. Frank Giblin, Douglas McMahon, Gary Pickard, and Barry Winkler and the anonymous reviewers for their critical comments; Dr. Paulo Kofuji for kindly providing transgenic dim starlight to bright daylight. This process, called light adaptation, is commonly thought to occur primarily in the retina. Retinal rod photoreceptors operate in dim light and cone photo-

mice for our research; and the Technology Commons College of Life Science at National Taiwan University for technical assistance with confocal laser scanning microscopy.

The authors declare no competing financial interests.

Correspondence should be addressed to either of the following: Dr. Dao-Qi Zhang, Eye Research Institute, 0akland University, 423 Dodge Hall, Rochester, MI 48309, E-mail: zhang@oakland.edu; or Dr. Shih-Kuo Chen Department of Life Science, National Taiwan University, No. 1 Sec. 4 Roosevelt Road, Taipei, Taiwan 10617, E-mail: alenskchen@ntu.edu.tw.

DOI:10.1523/JNEUROSCI.3500-15.2016

Copyright $\odot 2016$ the authors $\quad 0270-6474 / 16 / 367184-14 \$ 15.00 / 0$ 
receptors function in bright light. Both photoreceptors can adjust their sensitivity to more than seven decimal orders of illumination to continue to respond to brighter illumination (photoreceptor adaptation; Boynton and Whitten, 1970; Nakatani et al., 1991). In addition, postreceptoral neurons (horizontal, bipolar, amacrine, and ganglion cells) have the ability to adjust their sensitivity according to the ambient light condition through changes in their intrinsic membrane properties and modification of their synapses with other neurons (network adaptation; Green et al., 1975; Dunn et al., 2006).

Retinal ganglion cells (RGCs), the sole output neurons of the vertebrate retina, receive inputs from rod and cone photoreceptors through bipolar cells and amacrine cells, which are involved in network light adaptation. In addition, a small population of RGCs express the photopigment melanopsin which allows them to respond to light directly (Berson et al., 2002; Hattar et al., 2002). Like rods and cones, intrinsically photosensitive RGCs (ipRGCs) exhibit photoreceptor adaptation (Wong et al., 2005; Do and Yau, 2013). However, it is unclear how photoreceptor and network adaptation of ipRGCs contributes to light adaptation of the visual system (Allen et al., 2014). ipRGCs primarily project, via the optic nerve, to a variety of brain nuclei involved in non-image-forming visual functions such as circadian photoentrainment and the pupillary light reflex (Berson et al., 2002; Hattar et al., 2003; Panda et al., 2003). Intriguingly, recent studies demonstrated that ipRGCs send signals retrogradely to dopaminergic amacrine cells (DACs) within the retina (Zhang et al., 2008; Zhang et al., 2012; Atkinson et al., 2013; Newkirk et al., 2013). Intraretinal retrograde signal transmission provides a possible mechanism by which ipRGCs may influence light adaptation via the retinal dopaminergic system.

DACs are a subpopulation of retinal amacrine cells that constitute an intraretinal feedback pathway, transmitting rod and cone signals in the reverse direction from the inner to the outer retina (Dowling and Ehinger, 1975; Dacey, 1988; Witkovsky, 2004). With additional excitatory input from ipRGCs, this feedback pathway is expanded by transmitting melanopsin-based signals from the inner to the outer retina, acting as a centrifugal pathway (Zhang et al., 2008). The integrated signals from melanopsin, rods, and cones provide a driving force that stimulates DACs to release the key neurotransmitter dopamine through synaptic and extrasynaptic exocytosis volume transmission (Dkhissi-Benyahya et al., 2013). Released dopamine exerts its action through a family of G-protein-coupled dopamine receptors, D1-D5. Activation of these receptors by dopamine can reconfigure retinal circuits according to prevailing illumination by uncoupling electrical synapses throughout the retina (Lasater and Dowling, 1985; Mills and Massey, 1995; Krizaj et al., 1998; Mills et al., 2007), modulating excitatory glutamate receptors on horizontal cells (Knapp and Dowling, 1987), and regulating the activity of sodium channels of bipolar cells and ganglion cells (Hayashida and Ishida, 2004; Ichinose and Lukasiewicz, 2007). As a result, retina-specific dopamine deletion leads to an impairment of light-adapted vision (Jackson et al., 2012).

Despite the importance of signal transmission from ipRGCs to DACs, the exact route and synaptic mechanisms of this retrograde signaling pathway has been unknown. Axon collaterals have been reported previously in a small subpopulation of RGCs in mice, monkeys, and humans (Dacey, 1985; Peterson and Dacey, 1998; Joo et al., 2013). Our recent study demonstrated that some, if not all, of these collateral-bearing cells are M1 ipRGCs, one of five (M1-M5) subtypes (Joo et al., 2013). Here, we present convergent in vitro and in vivo physiological and anatomical evidence that axon collaterals of M1 ipRGCs make connections with DACs, forming a centrifugal pathway that conveys retrograde signals from the inner retina to the outer retina to potentially facilitate light-adapted vision.

\section{Materials and Methods}

Animals. Adult mice of both sexes were used in the present study. All animals were maintained on a 12:12 h light/dark cycle with ad libitum access to food and water. All procedures were conducted according to National Institutes of Health guidelines for work with laboratory animals and were approved by the Institutional Animal Care and Use Committees at Johns Hopkins University, National Taiwan University, and Oakland University.

For ipRGC recordings, a transgenic mouse line with a C57BL/6J background was used; melanopsin (Opn4)-expressing ipRGCs were labeled using green fluorescent protein (GFP; provided by Dr. Paulo Kofuji, University of Minnesota). For DAC recordings, two strategies were used to isolate melanopsin-based signaling to DACs. One strategy involved using C3H/HeJ mice homozygous for the Pde6b ${ }^{\text {rd1 }}$ mutation ( $r d 1$; Jackson Laboratory) in which rod loss occurs rapidly with onset at postnatal day 8 (P8) and is nearly complete by P21. By P90, virtually all outer photoreceptors disappear except for $\sim 3 \%$ of cone somata in the dorsal retina (Carter-Dawson et al., 1978). We crossed this line with our transgenic mouse in which DACs are genetically labeled using red fluorescent protein (RFP) under the control of the promoter for the rate-limiting enzyme for dopamine synthesis, tyrosine hydroxylase (TH; C57BL/6J background; Zhang et al., 2004), to obtain $r d 1$ TH::RFP transgenic mice. This mouse line carried a mixed C57BL/6J and C3H background and was used in the current study and our previous study (Atkinson et al., 2013). The other strategy involved genetically deleting Cnga3, a cone photoreceptor-specific cyclic nucleotide channel subunit, in our TH::RFP transgenic mice (Biel et al., 1999). We crossed our TH::RFP transgenic mice with a triple knock-out (Opn4 ${ }^{-1-}$ Gnat $^{-1-} \mathrm{Cnga3}^{-1-}$ ) mouse line (Hattar et al., 2003) to obtain cnga 3 knock-out TH::RFP transgenic mice. This mouse line had a mixed C57BL/6J and BL6/129 background. For morphological experiments, an Opn4-driven tamoxifen-inducible CreERT2 $\left(\mathrm{Opn} 4^{\mathrm{CETL}}\right)$ line was crossed with an alkaline phosphatase reporter $\left(\right.$ Rosa ${ }^{\mathrm{IAP}}$ ) line in a mixed BL/6; 129SvJ background (Joo et al., 2013). For our in vivo intraocular tetrodotoxin (TTX) injection experiment, rod- and cone-transducin double-knock-out ( gnat $^{-1-}$; gnat $2^{\text {cpfl31 }}$ cpfl3) mice were crossed with the Opn4-tau-LacZ mouse line to obtain melanopsin only (MO) mice (Calvert et al., 2000; Chang et al., 2006).

Generation of Opn4-DTA mouse. To generate Opn4-diphtheria toxin A (DTA) mice, we used the targeting arms and general strategy detailed in Hattar et al. (2002) and Güler et al. (2008). The DTA fragment (Maxwell et al., 1986) was inserted into the melanopsin gene locus using homologous recombination. The construct contained a $4.4 \mathrm{~kb}$ region immediately $5^{\prime}$ of the melanopsin start codon, the DTA fragment, an internal ribosomal entry site, tau-LacZ coding sequence, a self-excising neomycin resistance construct (Bunting et al., 1999), and the $1.5 \mathrm{~kb} 3{ }^{\prime}$ homologous arm starting from melanopsin exon 9. Specific targeting of the construct to the melanopsin locus was confirmed by PCR in both heterozygous $\left(O p n 4^{D T A /+}\right)$ mice. PCR primers were as follows: melanopsin forward primer: 5'-GAG CCA CTG AGC ATG TGT AGT C-3'; melanopsin reverse primer: $5^{\prime}$-CCC CAG GGG ATC TAG TCA AT-3'; DTA forward primer: 5'-GAG CCA CTG AGC ATG TGT AGT C-3'; and DTA reverse primer: 5'-CAT CGC ATC TTG GCC ACG TTT T-3'.

Patch-clamp recordings. To minimize the influence of a circadian effect, all experiments were performed during the day. Mice were adapted to the dark for $1-2 \mathrm{~h}$ before experiments and were then treated by $\mathrm{CO}_{2}$ overdose and cervical dislocation. Eyes were enucleated and hemisected at the ora serrata under infrared illumination. The cornea and lens were removed in a Petri dish filled with oxygenated extracellular solution containing the following (in mM): $125 \mathrm{NaCl}, 2.5 \mathrm{KCl}, 1 \mathrm{MgSO}_{4}, 2 \mathrm{CaCl}_{2}, 1.25$ $\mathrm{NaH}_{2} \mathrm{PO}_{4}, 20 \mathrm{D}$-glucose, and $26 \mathrm{NaHCO}_{3}$. The retina was separated from the sclera and placed ganglion cell side down ( $r d 1$ retinas) or photoreceptor side down (Opn4::GFP, wild-type, and $\mathrm{Cnga3}^{-1-}$ retinas) in a 
recording chamber and mounted on the stage of an upright conventional fluorescence microscope (Axio Examiner; Zeiss) within a light-tight Faraday cage. Oxygenated extracellular medium ( $\mathrm{pH} 7.4$ with $95 \% \mathrm{O}_{2}$ and $5 \% \mathrm{CO}_{2}$ ) continuously perfused the recording chamber at a rate of $2-3 \mathrm{ml}$ per min and the superfusate was maintained at $32^{\circ} \mathrm{C}$ by a temperature-control unit (TC-344A; Warner Instruments).

The retina was maintained in darkness for $\sim 1 \mathrm{~h}$ before recording. Cells and recording pipettes were viewed on a computer monitor connected to a digital camera (AxioCam; Zeiss) mounted on the microscope. The

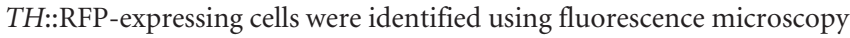
with a rhodamine filter set with a brief snapshot of fluorescence excitation light (1-5 s). Opn4::GFP-expressing cells were identified using a FITC filter. The identified cells and glass electrode were visualized using infrared differential interference contrast (DIC) optics for patch-clamp recording. Experiments were performed 10-15 min after fluorescence was used to locate the cells to allow the retinas to recover from photobleaching (caused by the brief exposure to fluorescence excitation light). The recovery may have been incomplete during this short dark adaptation period, so our experiments were likely performed in a partially dark-adapted state.

Whole-cell voltage-clamp recordings were obtained from the somas of DACs and ipRGCs using 4-7 M $\Omega$ electrodes and the signals were amplified using an Axopatch 200B amplifier (Molecular Devices). A holding potential of $-60 \mathrm{mV}$ was used for all recordings. The intracellular cesium solution used for DAC recordings contained the following (in $\mathrm{mM}$ ): 120 Cs-methane sulfonate, $5 \mathrm{NaCl}, 5 \mathrm{CsCl}, 10 \mathrm{HEPES}, 5 \mathrm{EGTA}, 0.5 \mathrm{CaCl}_{2}, 4$ Mg-ATP, 0.3 Na-GTP, and 5 lidocaine N-ethyl-chloride (QX-314). QX314 was used to improve the space clamp quality of the voltage-clamp and to block intrinsic action potentials (APs) of DACs, thus highlighting the extrinsic light-induced inward current of the cells. The $\mathrm{pH}$ of the intracellular solution was titrated to 7.2-7.4 with $\mathrm{CsOH}$. Data were not corrected for a liquid junction potential of $3.5 \mathrm{mV}$. For whole-cell current-clamp ipRGC recordings, $\mathrm{K}^{+}$-based intracellular solution was used that contained the following (in $\mathrm{mM}$ ): $120 \mathrm{~K}$-gluconate, $5 \mathrm{NaCl}, 4$ $\mathrm{KCl}, 10$ HEPES, 2 EGTA, $4 \mathrm{Mg}$-ATP, $0.3 \mathrm{Na}$-GTP, and $\sim 0.001 \%$ Alexa Fluor 488 hydrazide. All chemicals used in the recording solutions were purchased from Sigma-Aldrich unless otherwise noted. Data were acquired using a Digidata 1440A digitizer (Molecular Devices) and analyzed offline using Clampex 10 software (Molecular Devices).

Cadmium chloride and nifedipine were purchased from SigmaAldrich. Alexa Fluor 488 hydrazide was obtained from Life Technologies. $\omega$-conotoxin GVIA, $\omega$-agatoxin IVA, and SNX 482 were purchased from Abcam and L-AP4, TTX, and mibefradil dihydrochloride were obtained from Tocris Bioscience. Concentrated stock solutions were prepared for all drugs used, which were later diluted in the extracellular medium as required, except for nifedipine, which was diluted in DMSO.

Light stimulation. Light stimuli were generated using a $470 \mathrm{~nm}$ LED (LED Supply and LC Corporation) to stimulate the melanopsin chromophore (peak sensitivity of $\sim 480 \mathrm{~nm}$ ). An LED controller (Mightex) was used to drive the LED and the light intensity was adjusted by varying the driving current. The light intensity was measured at the surface of the retina by using an optical power meter (units converted from $\mu \mathrm{W} / \mathrm{cm}^{2}$ to photons $\mathrm{cm}^{-2} \mathrm{~s}^{-1}$; model $843-\mathrm{R}$; Newport). A light intensity of $4.7 \times$ $10^{13}$ photons $\mathrm{cm}^{-2} \mathrm{~s}^{-1}$ was used for all experiments.

$E R G$ recordings. Electroretinogram (ERG) recordings were all conducted at circadian time 6 (CT 6) to minimize circadian influence. On the day of the experiment, mice were kept in darkness. Mice were intraperitoneally administered with a mixture of ketamine $(37.5 \mathrm{mg} / \mathrm{kg})$ and $\mathrm{xy}-$ lazine $(7.77 \mathrm{mg} / \mathrm{kg})$. The pupils were dilated with $1 \%$ atropine and $0.5 \%$ proparacaine-hydrochloride was used as a local anesthetic. Eyes were kept moist with $1.5 \%$ hydrocellulose eye drops. A silver electrode was used to record ERG responses and needle electrodes were placed in the cheek and tail as reference and ground leads, respectively. For lightadapted ERGs, a white LED light source was placed in a homemade gaze-field that provides $0.7 \log \mathrm{cd} \mathrm{s} / \mathrm{m}^{2}$ light stimulation (above melanopsin threshold; Tu et al., 2005) with another $25 \mathrm{~cd} / \mathrm{m}^{2}$ white LED as steady background to saturate the rod response sufficiently. Flash intensity and duration were controlled by a Grass Instruments S44 stimulator. During $20 \mathrm{~min}$ of light adaptation, $5 \mathrm{~ms}$ of flash stimulation was provided at a frequency of $0.75 \mathrm{~Hz}$. Signals were amplified, filtered (bandwidth:
$0.3-1000 \mathrm{~Hz})$, and digitized $(10 \mathrm{kHz})$ with a Grass Instruments $\mathrm{P} 5$ preamplifier. Data were collected in a 2 min averaged bin. B-wave amplitudes were analyzed offline. Each trace was digitally filtered with a $60 \mathrm{~Hz}$ low-pass filter to remove the influence of oscillatory potentials. B-wave amplitudes were calculated by subtracting the peak of the b-wave (within $200 \mathrm{~ms}$ after light stimulation) and the trough of the a-wave. Baseline b-wave was calculated by averaging the first 10 ERG recordings from each trial for normalization. PD168077 $(2 \mathrm{mg} / \mathrm{kg}$ ) dissolved in $1 \times$ PBS (Tocris Bioscience) was injected intraperitoneally just before the ERG recordings. Data analyses were performed using Prism 6.0 software (GraphPad Software).

Immunohistochemistry. For whole-mount staining, mice were perfused with PBS for $2 \mathrm{~min}$, followed by $4 \%$ paraformaldehyde (PFA) for 15 $\mathrm{min}$, and then the eyes were enucleated. The entire eye was prefixed for 30 $\mathrm{min}$ in $4 \%$ PFA before the retina was removed and postfixed in 4\% PFA for $30 \mathrm{~min}$. After fixation, retinas were blocked in 5\% goat serum, $1 \%$ BSA, and $0.2 \%$ Triton X-100 in PBS (0.1 M) for 2-6h at room temperature. Subsequently, the retina was incubated overnight at $4^{\circ} \mathrm{C}$ in a blocking solution containing the following antibodies: chicken anti- $\beta$ galactosidase (1:500; Abcam), rabbit anti-c-Fos (1:10,000; Millipore), mouse anti-TH (1:1000; Immunostar), chicken anti-synaptophysin (1: 1000; Abcam), rabbit anti-PSD95 (1:200; Abcam), and mouse antibassoon (1:400; Enzo), as indicated in the main text. After washing in PBS $(0.1 \mathrm{M})$, retinas were incubated with the corresponding secondary antibodies conjugated with Alexa Fluor 488, 568, 594, or 633 (Invitrogen) at room temperature for $2 \mathrm{~h}$ and mounted with Vectashield (Vector Laboratories) for imaging. For whole-mount immunofluorescence staining of ipRGC axon collaterals, alkaline phosphatase staining was performed first (see below), followed by the antibody-staining protocols described above. For cross-sectional examination, alkaline phosphatase staining was performed, the retina was mounted with glycerol, and the location of the ipRGC axon collateral was marked in DIC images. After imaging, retinas were washed with PBS, placed between two coverslips with optimal cutting temperature (O.C.T.) compound (Sakura), frozen using dry ice, and the retina was embedded in an O.C.T. block for cryostat sectioning. Next, the sections were air dried and incubated in blocking solution. After blocking, antibody-staining protocols were followed as indicated above.

Confocal imaging. Immunofluorescence was examined using a Zeiss LSM 780 confocal laser scanning microscope. The excitation/detection wavelength settings were $488 \mathrm{~nm} / 490-534 \mathrm{~nm}$ for c-Fos, $561 \mathrm{~nm} / 564$ $614 \mathrm{~nm}$ for $\mathrm{TH}$, and $633 \mathrm{~nm} / 622-741 \mathrm{~nm}$ for LacZ triple staining and were visualized with a $20 \times$ Plan-Apochromat objective. The excitation/ detection wavelength settings were $488 \mathrm{~nm} / 490-534 \mathrm{~nm}$ for bassoon, $561 \mathrm{~nm} / 564-614 \mathrm{~nm}$ for TH, and $633 \mathrm{~nm} / 623-644 \mathrm{~nm}$ for alkaline phosphatase (ipRGC staining) and were visualized with a $100 \times$ PlanApochromat objective. The excitation/detection wavelength settings were $594 \mathrm{~nm} / 615-638 \mathrm{~nm}$ for TH, $488 \mathrm{~nm} / 503-547 \mathrm{~nm}$ for synaptophysin, $561 \mathrm{~nm} / 578-595 \mathrm{~nm}$ for PSD-95, and $633 \mathrm{~nm} / 623-644 \mathrm{~nm}$ for ipRGC collateral in quadruple staining and were visualized with a $40 \times$ Plan-Apochromat objective. Pseudocoloring was applied for visualization using Zeiss ZEN blue software. Rendered 3D views were obtained using ImageJ software from 29 stacked images with a $0.08 \mu \mathrm{m}$ interval taken using a $100 \times$ Plan-Apochromat objective. For all confocal images, the pinhole for all channels was set at 1 arbitrary unit.

In vivo TTX injection. After an overnight dark adaptation, mice were anesthetized, a polished glass needle was used to pierce the eye behind the ora serrata, and $1 \mu$ l of TTX ( 2 mM in $1 \times$ PBS) was injected into one eye and $1 \mu \mathrm{l}$ of PBS $(0.1 \mathrm{M})$ was injected into the other eye as a control using a syringe pump (KD Scientific) with a $10 \mu \mathrm{l} / \mathrm{min}$ flow rate. After injection, mice were placed under 400 lux white fluorescent light for $90 \mathrm{~min}$ and then retinas were obtained from the mice for immunostaining with TH, c-Fos, and $\beta$-galactosidase antibodies.

Tamoxifen injections. Tamoxifen was dissolved in sunflower oil to obtain a $10 \mathrm{mg} / \mathrm{ml}$ concentration. Labeling intensity was dependent on the amount of tamoxifen injected intraperitoneally and on the efficiency of excision from the LoxP regions in the reporter mice. At P28, mice were injected with $500 \mu \mathrm{l}$ of tamoxifen. After $10 \mathrm{~d}$, retinas were dissected out from eyeballs of the mice for alkaline phosphatase staining. 
A
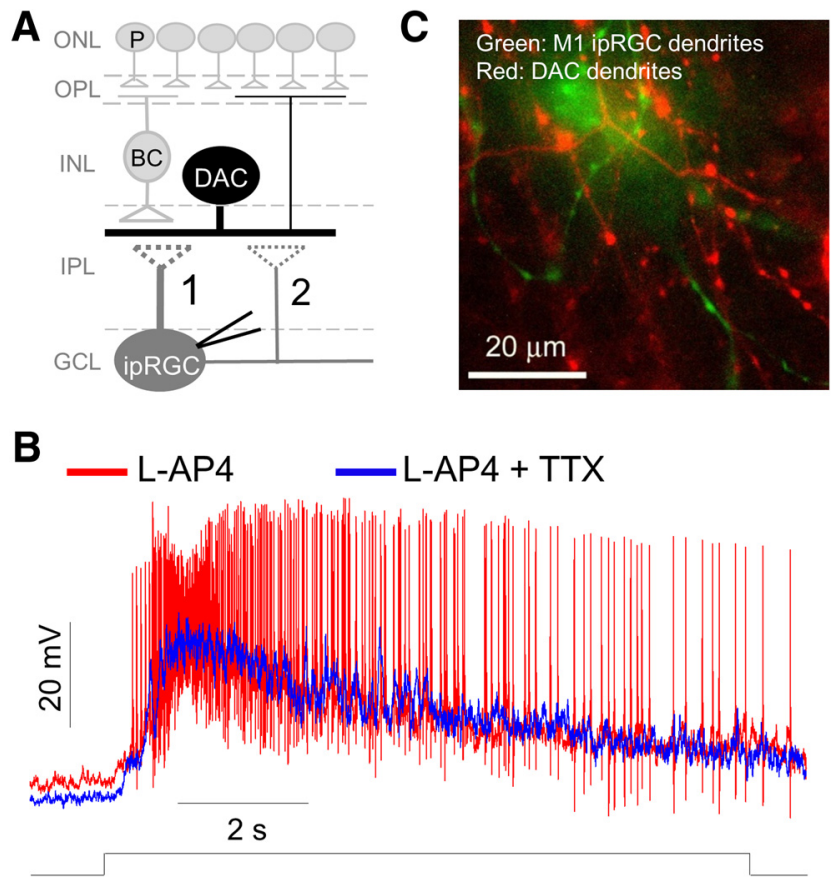

Figure 1. Tetrodotoxin (TTX) does not affect light-evoked graded potentials of M1 ipRGCs while blocking action potentials (APS). A, Diagram depicting potential dendrodendritic contact (1) and/or axon collateral-dendrite contact (2) between an ipRGC and a DAC. P, photoreceptors; $B C$, bipolar cell; ONL, outer nuclear layer; $\mathrm{OPL}$, outer plexiform layer; $\mathrm{INL}$, inner nuclear layer; $\mathrm{GCL}$, ganglion cell layer. $\boldsymbol{B}$, Current-clamp recording of an M1 ipRGC in the presence of $50 \mu \mathrm{m} \mathrm{L-AP4}$ with a light-induced slow membrane depolarization accompanied by APs (red trace). Coapplication of $1 \mu \mathrm{M}$ TTX blocked the light-induced APs but had no effect on the membrane depolarization (blue trace). Stimulation bar shows timing of light pulse $\left(470 \mathrm{~nm} ; 4.7 \times 10^{13}\right.$ photons $\left.\mathrm{cm}^{-2} \mathrm{~s}^{-1}\right)$. C, Merged image demonstrating that the recorded ipRGC was an M1-type because its Alexa Fluor 488-labeled dendrites (green) costratified with RFP-labeled DAC dendrites (red) in the OFF layer of the IPL.

Alkaline phosphatase staining. Alkaline phosphatase staining was performed as described previously (Chen et al., 2011). In brief, mice were perfused with $6 \mathrm{ml}$ of PBS and $45 \mathrm{ml}$ of $4 \%$ PFA and the retina was isolated. Whole-mount retinas were fixed for $30 \mathrm{~min}$, heat inactivated at $60^{\circ} \mathrm{C}$ for $45 \mathrm{~min}$, and incubated in an alkaline phosphatase staining solution (NBT/BCIP tablet; Roche) overnight in darkness. After staining, retinas were postfixed in 4\% PFA for $2 \mathrm{~h}$ and mounted in 50\% glycerol.

Statistical analyses. Electrophysiological data were analyzed using the Clampfit 10.4 and SigmaPlot 12.0 (Systat Software) software packages. To assess the effects of drugs, the significance of the reduction of the light-induced inward current amplitude was determined using a paired $t$ test or a Wilcoxon signed-rank test when the data were normally and not normally distributed, respectively. Values of the normally distributed data are presented as the mean \pm SEM. $p<0.05$ was considered statistically significant.

\section{Results}

Retrograde signaling from ipRGCs to DACs is AP dependent We have proposed previously that ipRGCs send retrograde signals to DACs through dendrodendritic synapses, axon collaterals of ipRGCs, or both (Fig. 1A; Zhang et al., 2012). The intrinsic ipRGC light response is characterized by a sustained graded potential that is accompanied by an increased firing frequency of APs. If signal transmission occurs via the dendrodendritic route, ipRGCs likely drive DACs through the graded potential with the possibility of increased dendritic spikes (Stuart and Sakmann, 1994). If transmission occurs via axon collaterals, signaling is likely mediated by increased AP frequency. APs are generated by voltage-gated sodium channels and therefore can be abolished by the specific sodium channel blocker TTX. TTX is unlikely to affect light-induced graded potentials of ipRGCs because they are generated by transient receptor potential channels (Warren et al., 2006; Xue et al., 2011). To test this hypothesis, we used a doubletransgenic mouse in which Opn4-expressing RGCs and DACs are genetically labeled with GFP and RFP, respectively (Zhang et al., 2004; Schmidt et al., 2008). To identify the M1 subtype, we included Alexa Fluor 488 in the pipette solution for whole-cell recordings. Alexa Fluor 488 diffused throughout the cell body and processes to reveal the entire morphology of the GFP-labeled ipRGCs. Of the five subtypes of ipRGCs (M1-M5), M1 ipRGCs are distinguished from other subtypes by their dendrites, which terminate exclusively in the $\mathrm{S} 1$ sublamina of the inner plexiform layer (IPL; Viney et al., 2007; Ecker et al., 2010). Alexa Fluor 488-labeled dendrites costratified with the RFP-labeled dendrites of DACs (Fig. 1C), indicating that the recorded cells were indeed M1 ipRGCs. To reveal the intrinsic photoresponses of M1 ipRGCs, rod and cone inputs to ipRGCs were blocked using the ON pathway blocker L-AP4 (50 $\mu \mathrm{M}$; Slaughter and Miller, 1981). Figure $1 B$ illustrates a characteristic light response of a M1 ipRGC to $10 \mathrm{~s}$ of $470 \mathrm{~nm}$ light $\left(4.7 \times 10^{13}\right.$ photons $\left.\mathrm{cm}^{-2} \mathrm{~s}^{-1}\right)$ with a prolonged membrane depolarization accompanied by an increased AP frequency (Fig. 1B, red trace). Application of $1 \mu \mathrm{M}$ TTX completely blocked the light-induced APs, but did not affect the light-induced membrane depolarization (Fig. 1B, blue trace). The effect of TTX was completely reversible. These results were observed in all seven M1 cells tested.

Our results demonstrate that the light-induced graded potential of ipRGCs persists in the presence of TTX. If the ipRGC graded potential could mediate signal transmission to DACs, then the ipRGC-driven responses of DACs should be detectable in the presence of TTX. To test this possibility, we used a transgenic mouse in which DACs are marked by RFP to facilitate their identification for patch-clamp recordings (Zhang et al., 2004; Fig. $2 A)$. We included the intracellular sodium channel blocker QX314 in the intracellular pipette solution for all DAC recordings to ensure that voltage-gated $\mathrm{Na}^{+}$channels were already blocked within DACs before extracellular application of TTX (Fig. 2B). Therefore, the effect of TTX observed below was not due to blockage of voltage-gated $\mathrm{Na}^{+}$channels within the DACs. Any possible rod and cone input was blocked using L-AP4 $(50 \mu \mathrm{M})$. Figure $2 C$ (left) illustrates a wild-type DAC that exhibited a lightinduced transient excitatory inward current, followed by a prolonged desensitizing current that was accompanied by miniature EPSC events in response to $3 \mathrm{~s}$ of $470 \mathrm{~nm}$ light $\left(4.7 \times 10^{13}\right.$ photons $\mathrm{cm}^{-2} \mathrm{~s}^{-1}$ ). In the presence of $1 \mu \mathrm{M}$ TTX, the transient current and the miniature EPSC events were abolished (Fig. 2C, center). The effect of TTX was reversible after washout (Fig. 2C, right). The same results were observed in three other wild-type DACs, suggesting that the TTX-resistant ipRGC graded potential (Fig. $1 B$ ) failed to evoke excitatory currents in DACs.

Because L-AP4 only blocks the ON bipolar cell-mediated excitatory response of DACs, we sought to further rule out a possible contribution of disinhibitory input from the OFF channel to the ON response. To do so, we used $r d 1$ mice in which rod and cone photoreceptors degenerate soon after birth, leaving ipRGCs as the only photoreceptive input to DACs (Carter-Dawson et al., 1978; Atkinson et al., 2013). Upon stimulation with $470 \mathrm{~nm}$ light for $3 \mathrm{~s}$, an $r d 1$ DAC had a strong transient light-induced inward current of $79.46 \mathrm{pA}$, followed by a sustained response. During the sustained response, there was a barrage of miniature EPSC events (Fig. 2D, left). Again, the application of $1 \mu \mathrm{M}$ TTX resulted in the complete abolishment of the transient and sustained inward currents (Fig. 2D, center). The abolishment was partially restored 

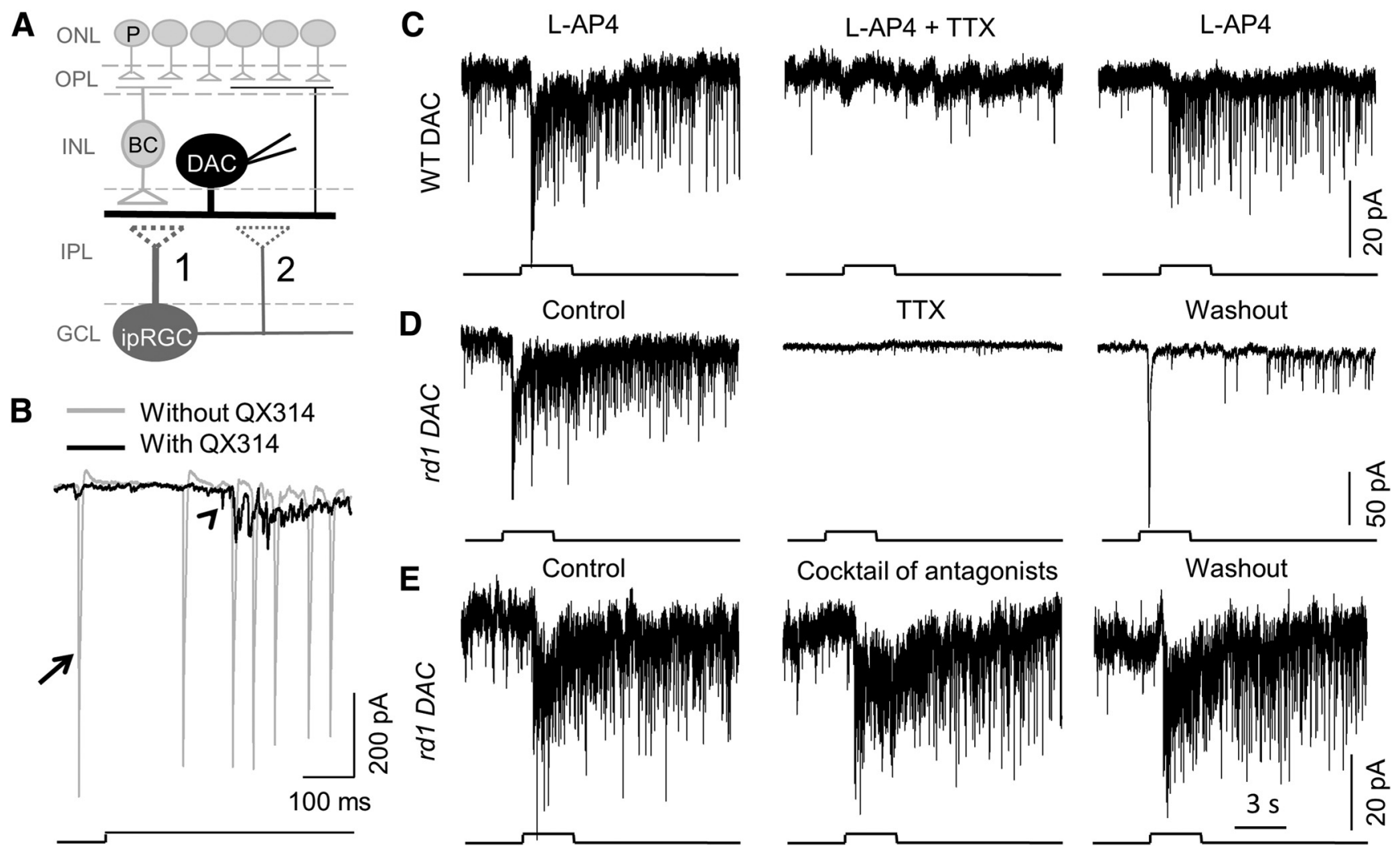

Figure 2. AP-dependent signal transmission from ipRGCs to DACs. A, Whole-cell voltage-clamp recordings were performed on DACs. B, Gray trace showing spontaneous and light-induced action currents (arrow) of a DAC recorded using an intracellular pipette solution without QX-314; the black trace demonstrates spontaneous and light-evoked EPSCS (arrowhead) of a DAC with an intracellular pipette solution containing $5 \mathrm{~mm}$ QX-314. For all of the following DAC recordings, $5 \mathrm{~mm}$ QX-314 was included in the pipette solution. C, ADAC in a wild-type retina, with rod and cone input blocked with $50 \mu \mathrm{m} \mathrm{L-AP4}$, exhibited a light-induced slow inward current superimposed with miniature EPSC events (left). Application of TTX completely blocked the slow inward current and miniature EPSC events (center). TTX's effect was reversed upon washout (right). The same results were observed from DACs in $r d 1$ retinas; an example is shown in $\boldsymbol{D}$ (left trace, control; center trace, $1 \mu \mathrm{M} \mathrm{TTX}$; and right trace, washout). $E$, In another $r$ d 1 DAC, the ipRGC-mediated inward current and EPSC events were persistent in the presence of inhibitory antagonists (20 $\mu \mathrm{m}$ GABAzine for GABA $A_{\mathrm{A}}$ receptors, $50 \mu \mathrm{m}$ TPMPA for $\mathrm{GABA}_{C}$ receptors, and $1 \mu \mathrm{m}$ strychnine for glycine receptors). Light stimulus duration was $3 \mathrm{~s}$ for $\mathbf{C}-\boldsymbol{E}$. Stimulation bar shows timing of light pulse $\left(470 \mathrm{~nm}\right.$; $4.7 \times 10^{13}$ photons $\left.\mathrm{cm}^{-2} \mathrm{~s}^{-1}\right)$.

upon washout (Fig. 2D, right). The results were consistent in all cells tested $(n=6)$.

Our results suggest that ipRGC input to DACs is AP dependent. However, because a recent study showed that ipRGC responses can be transmitted through gap junctions to spiking, wide-field amacrine cells (Reifler et al., 2015), it was possible that ipRGCs could be signaling polysynaptically to DACs through wide-field inhibitory amacrine cells. To test this possibility, we applied a mixture of antagonists of inhibitory receptors $(20 \mu \mathrm{M}$ GABAzine for $\mathrm{GABA}_{\mathrm{A}}$ receptors, $50 \mu \mathrm{M}$ TPMPA for $\mathrm{GABA}_{\mathrm{C}}$ receptors, and $1 \mu \mathrm{M}$ strychnine for glycine receptors). The ipRGCmediated inward current and miniature EPSCs of an $r d 1$ DAC remained intact in the presence of the inhibitory antagonists (Fig. $2 E)$. The results were consistent in all cells tested $(n=5)$, suggesting that ipRGCs are unlikely to signal to DACs polysynaptically through electrically coupled amacrine cells (Müller et al., 2010; Reifler et al., 2015).

To confirm that ipRGC input to DACs is AP dependent in $v i v o$, we performed double-immunofluorescence staining with antibodies against TH and c-Fos, an indirect marker of neuronal activity (Hunt et al., 1987), in whole-mount retinas of Gnat 1 and

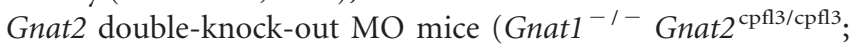
Calvert et al., 2000; Chang et al., 2006). In this transgenic mouse line, phototransduction in rods and cones is genetically eliminated by knock-out of the G-protein transducin; therefore, the only functional photoreceptor in the MO retina is the ipRGC.
To observe c-Fos expression in ipRGCs simultaneously, we crossed the MO line with an Opn4-tau-LacZ line, in which $\beta$-galactosidase is predominantly expressed in M1 ipRGCs (Gnat $^{-1-}$ Gnat2 ${ }^{\text {cpfl3/cppll3 }} \mathrm{Opn} 4^{\text {tau }- \text { LacZ/+ }}$; Calvert et al., 2000; Chang et al., 2006). As expected, all DACs and M1 ipRGCs were negative for c-Fos without light exposure (data not shown). After light exposure (400 lux white) for $90 \mathrm{~min}$, most M1 ipRGCs were positive for c-Fos (Fig. $3 E$ ), whereas approximately half of DACs were c-Fos positive in the MO mice (Fig. 3A,C,D). This result suggests that ipRGCs can transmit light signals and increase the activity of DACs independently of functional rods and cones. However, light activation of DACs via ipRGCs, as indicated by c-Fos staining, was blocked by intraocular injection of TTX before light exposure (Fig. $3 B-D$ ), whereas most M1 ipRGCs remained c-Fos positive (Fig. 3F). This in vivo result is consistent with the physiological data and suggests that retrograde signaling from ipRGCs to DACs is AP dependent. Together, the electrophysiological and immunofluorescence data indicated that ipRGCs convey retrograde light information to DACs through TTX-sensitive signal transmission, presumably through APs propagated along intraretinal axon collaterals.

Axon collaterals of ipRGCs make potential synaptic contact with DACs

To further illustrate the connection between ipRGC axon collaterals and DACs, we sparsely labeled ipRGCs in Opn $4^{\mathrm{CETL} /+}$ Rosa2 $6^{\mathrm{IAP} /+}$ 

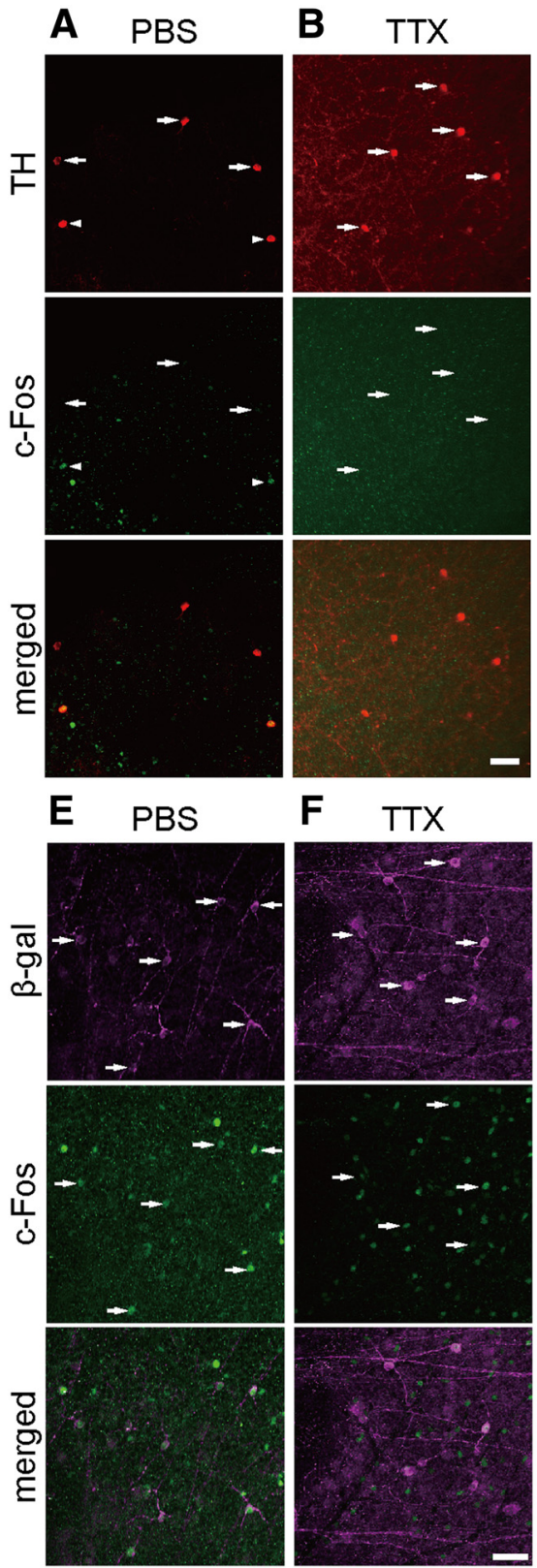

C
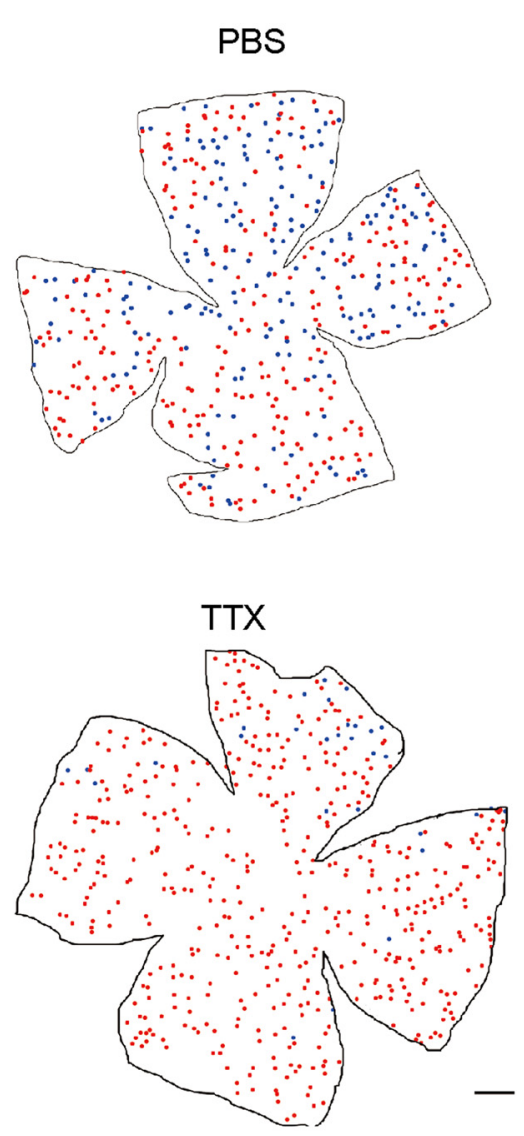

D

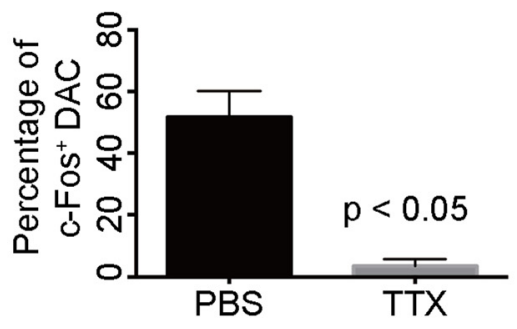

Figure 3. TTX ablates melanopsin-mediated activity of DACs in vivo. $\boldsymbol{A}$, Whole-mount retina with TH, $\beta$-galactosidase, and c-Fos triple immunofluorescence staining from a rod and cone transducin double knock-out and 0pn4-tau-LacZ background mouse $\left(0 p n 4^{\text {tau }- \text { LacZ/+ }}\right.$ Gnat $^{-/-}$Gnat2 $\left.^{-/-}\right)$. At the IPL, some TH + DACs (indicated by white arrowheads) were colabeled with c-Fos (green) after 90 min of white light (400 lux) exposure after intraocular injection of PBS. $\boldsymbol{B}$, Intraocular injection of TTX before light exposure blocked c-Fos expression in DACs (indicated by white arrows). C, Illustration depicting the distribution of DACs in the whole-mount retina after light exposure from a PBS-injected retina (top) and a TTX-injected retina (bottom). Red dots indicate c-Fos-negative DACs, blue dots indicate c-Fos-positive DACs. In the TTX-injected retina, almost all DACs were c-Fos negative. D, Quantification of c-Fos-positive DACs after 90 min white light exposure. The percentage of c-Fos-positive DACs in the TTX injection group ( $n=3$ ) was near zero and was significantly lower than in the PBS injection group $(n=3) . \boldsymbol{E}, \boldsymbol{F}$, Most M1 ipRGCs, labeled by $\beta$-galactosidase antibody (magenta), are c-Fos (green) positive after $90 \mathrm{~min}$ of light exposure (indicated by white arrows) in both the PBS control group (E) and the TTX intraocular injection group (F). Scale bars: $\boldsymbol{A}, \boldsymbol{B}, 50 \mu \mathrm{m} ; \boldsymbol{C}, 1000 \mu \mathrm{m} ; \boldsymbol{E}, \boldsymbol{F}, 50 \mu \mathrm{m}$.

transgenic mice using alkaline phosphatase staining to identify ipRGC axon collaterals (Fig. 4A). After locating an ipRGC axon collateral (Fig. $4 B-D$, magenta arrowheads), we sectioned the area of interest and performed triple immunofluorescence staining with antibodies against TH (DACs), synaptophysin (presynaptic marker), and PSD-95 (postsynaptic marker; Fig. 4F-L). Because NBT deposition from alkaline phosphatase staining can reflect far-red light such as that from a $633 \mathrm{~nm}$ helium-neon laser, we set a confocal microscope to emit $633 \mathrm{~nm}$ helium-neon laser light and detect the $633 \mathrm{~nm}$ reflection signal. We adjusted the pinhole to obtain an optic slice image from the colorimetric alkaline phosphatase staining that was similar to that obtained from fluorophore-based immunostaining (Fig. 4E; Jékely and Arendt, 2007). Using these methods, we observed multiple ipRGC axon collaterals colocalized with synaptophysin in direct apposition to a DAC dendrites colocalized with PSD-95 in the OFF layer of the IPL (Fig. $4 F-L$ ), indicating that ipRGC axon collaterals form synaptic connections with DACs. To further demonstrate the close proximity of the presynaptic marker and postsynaptic marker, we reconstructed the putative synaptic site shown in Figure $4 F$ using high-resolution confocal images ( 29 images per stack using a $0.08 \mu \mathrm{m}$ interval) and analyzed it in 3D rotation (Henny and Jones, 2006). Contact between synaptophysin and PSD-95 (colocalized with an ipRGC axon collateral shown in Fig. $4 F$ ) was shown using three orthogonal angles (Fig. 5E1-E3), with PSD-95 puncta located on the $\mathrm{TH}^{+}$DAC dendrites (Fig. 5B1-B3). To quantify the number of putative presynaptic contacts between ipRGC axon collaterals and DACs, we performed whole-mount staining using bassoon as a presynaptic marker, TH for DACs, and alkaline phosphatase for ipRGCs (Fig. 6A). Quantitative data show that, at the ipRGC-DAC contact sites, the number of bassoon puncta colocalized with ipRGC axon collaterals (Fig. 6B, ipRGC axonipRGC) was significantly higher than bassoon puncta colocalized with ipRGC dendrites (Fig. $6 B$, ipRGC dendrite - ipRGC; $p<0.01, n=3)$. In addition, we rarely observed presynaptic marker colocalization with DACs in contact with ipRGC axon collaterals (Fig. $6 B$, ipRGC axon - DAC; $p<$ $0.01, n=3)$; more frequently, we found DACs to be presynaptic to ipRGC dendrites, as has been reported previously (Fig. 6B, ipRGC dendrite - DAC; Vugler et al., 2007; Van Hook et al., 2012). Our results further support the notion that ipRGCs are presynaptic to DACs through their axon collaterals.

Together, our physiological and anatomical data indicate that retrograde signaling from axon collateral-bearing M1 ipRGCs to DACs is likely mediated by APs and that the melanopsin-driven ipRGC phototransduction system is sufficient to modulate DAC activity. These results support the hypothesis that ipRGC axon collaterals are the conduit for retrograde signal transmission from ipRGCs to DACs.

\section{Retrograde signal transmission is mediated by VGCCs}

Next, we sought to determine whether signal transmission from ipRGCs to DACs is mediated by voltage-gated calcium channels 
A

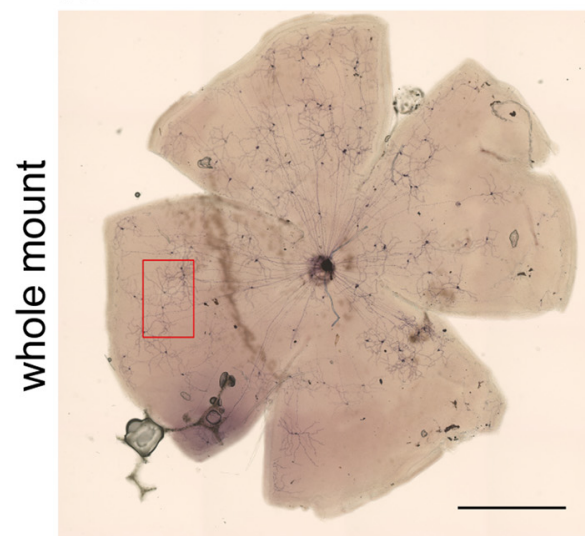

B

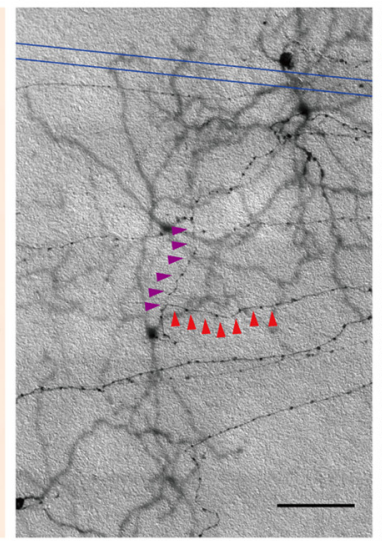

C

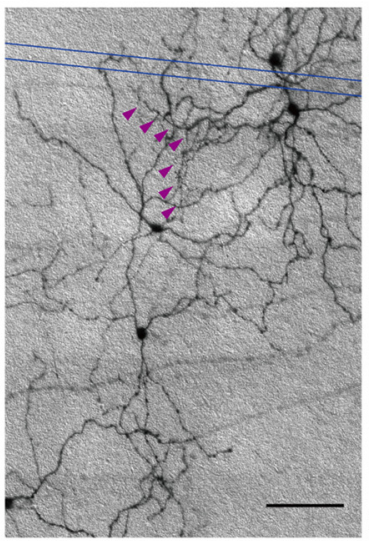

D

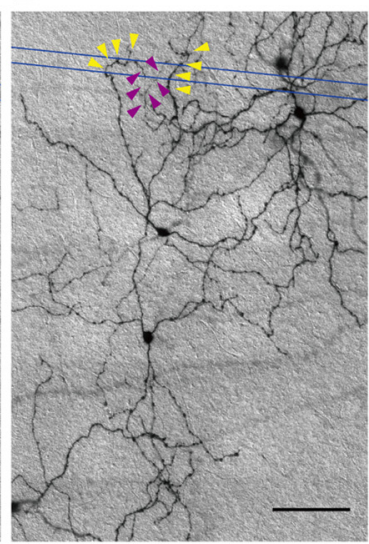

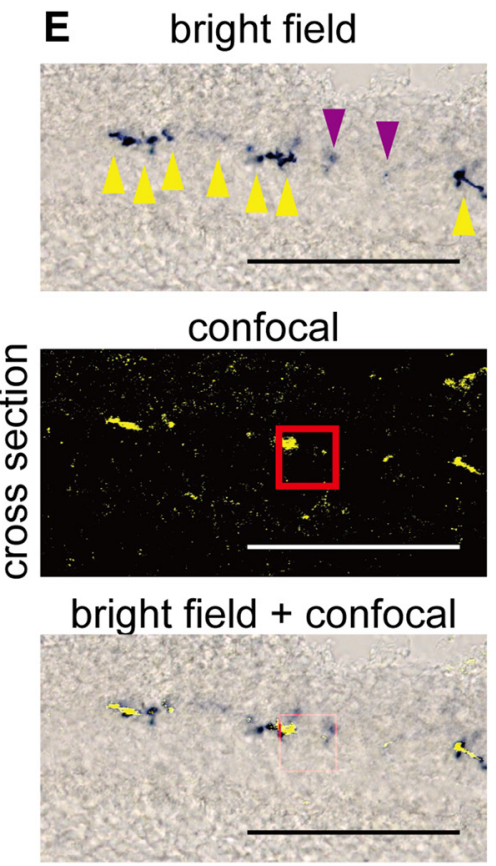

F merged
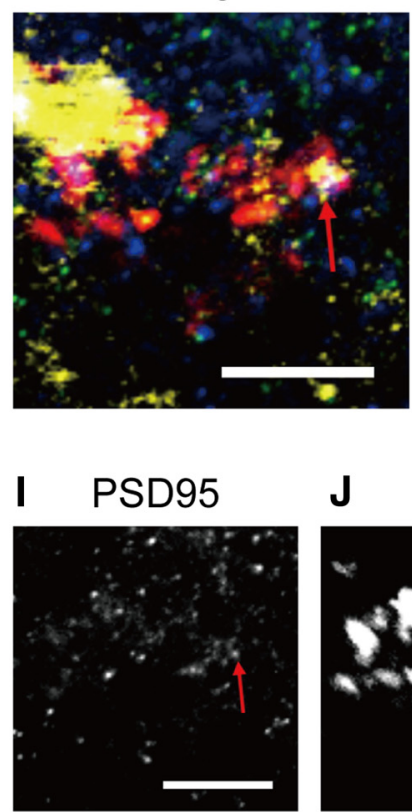

G PSD95 + TH
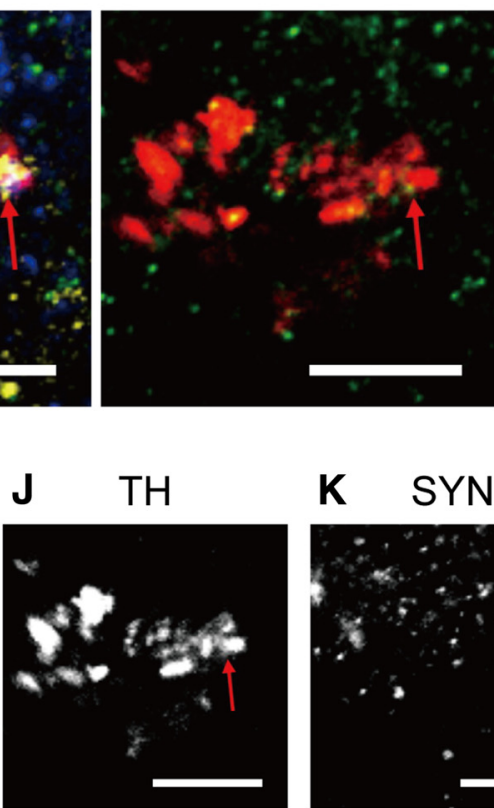

H $\quad$ SYN + AP

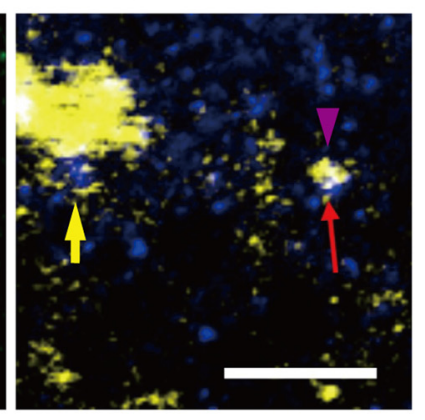

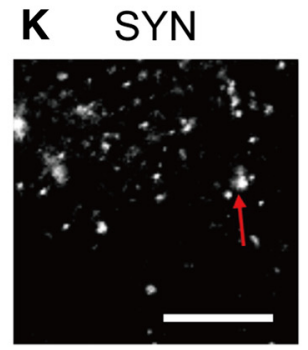

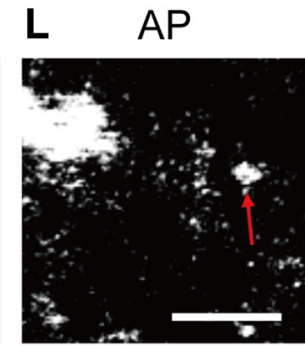

Figure 4. Representative image for colocalization of an ipRGC axon collateral, DAC, presynaptic marker, and postsynaptic marker in the IPL. $A$, Alkaline phosphatase staining in a whole-mount retina isolated from an $0 p n 4^{C E T L+} ;$ Rosa $26^{I A P /+}$ mouse, in which ipRGCs were sparsely labeled to identify axon collaterals. $\boldsymbol{B}-\boldsymbol{D}$, Consecutive DIC images of the axon collateral from the red box in $\boldsymbol{A}$ are shown in high magnification. An ipRGC axon collateral (magenta arrowheads) branched from the primary axon (red arrowheads in $\boldsymbol{B}$ ). Dendrites from an ipRGC near the axon collateral are indicated by yellow arrowheads ( $\boldsymbol{D}$ ). Putative synaptic sites were further investigated by sectioning the retina between the blue lines. $\boldsymbol{E}$, Bright-field image of NBT/BCIP staining of an ipRGC axon collateral (top) and a confocal image obtained from the same slice using $633 \mathrm{~nm}$ reflection mode (center). The merged image (bottom) shows a similar pattern, although the confocal image was much clearer than the bright-field image. Yellow arrowheads indicate dendrites and magenta arrowheads indicate part of an axon collateral. $\boldsymbol{F}$ - $\boldsymbol{L}$, High-magnification confocal images from the red square in $\boldsymbol{E}$ at the boundary of the IPL. Red arrow indicates the colocalization of the postsynaptic marker PSD-95 (green; $\boldsymbol{I}$ ), a TH ${ }^{+}$DAC (red; $\boldsymbol{J}$ ), the presynaptic marker synaptophysin (yellow; $\boldsymbol{K}$ ), and the $633 \mathrm{~nm}$ reflection signal from NBT deposition of an axon collateral (blue; $\boldsymbol{L}$ ). In $\boldsymbol{H}$, a yellow arrow indicates an ipRGC dendrite and a magenta arrowhead denotes axon collateral. SYN, Synaptophysin; AP, alkaline phosphatase. Scale bars: $\boldsymbol{A}, 1000 \mu \mathrm{m} ; \boldsymbol{B}-\boldsymbol{E}, 100 \mu \mathrm{m} ; \boldsymbol{F}-\boldsymbol{L}, 10 \mu \mathrm{m}$.

(VGCCs). Calcium influx in response to membrane depolarization is mediated by VGCCs. When VGCCs open, calcium in the extracellular environment moves down the calcium concentration gradient into the low-calcium cell interior. In a low-calcium scenario, an AP depolarizes the cell terminal and VGCCs open, but few calcium ions are available to enter the cell terminal to facilitate glutamate release, resulting in reduced signal transmission. Therefore, we tested whether the ipRGC-mediated lightinduced inward current of DACs was decreased in a low extracellular calcium condition. In response to $3 \mathrm{~s}$ of $470 \mathrm{~nm}$ light, an $r d 1$ DAC in control extracellular solution $\left(2 \mathrm{mM} \mathrm{Ca}^{2+}\right)$ exhibited a large ipRGC-mediated inward current (212.4 pA) with miniature EPSC events (Fig. 7A, left). When the extracellu- lar media was switched to a low calcium solution $\left(0.5 \mathrm{~mm} \mathrm{Ca}^{2+}\right.$ and $1.5 \mathrm{mM} \mathrm{Mg}^{2+}$; Fig. $7 A$, center), the amplitude of the peak inward current was attenuated $(74.91 \mathrm{pA})$ and the number of the EPSC events were profoundly decreased. The effect of low extracellular calcium was fully reversible upon washout (Fig. $7 A$, right). Pooled data demonstrate that low extracellular calcium reduced the amplitude of ipRGC-mediated inward current by an average of $64.8 \%$ (Fig. $7 B ; n=8 ; p<0.01$, Wilcoxon signed-rank test).

To further assess the role of $\mathrm{Ca}^{2+}$ channels in retrograde signal transmission, we applied the divalent cation cadmium $\left(\mathrm{Cd}^{2+}\right)$ to block all VGCCs nonspecifically (Fig. $\left.7 C\right)$. In an $r d 1$ retina, a control recording shows a DAC with a light-induced 

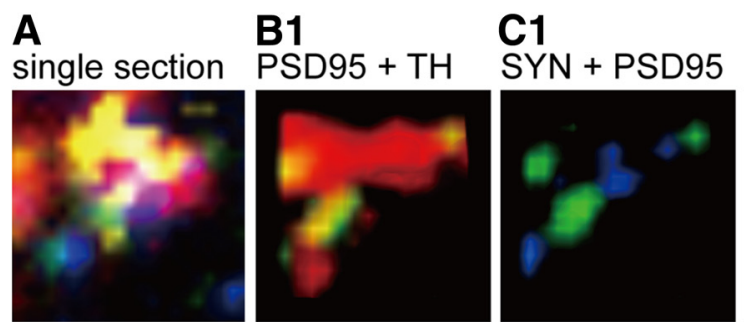

D1

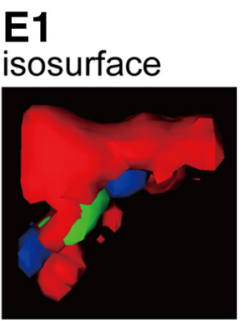

F1

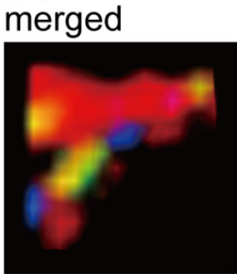
orientation

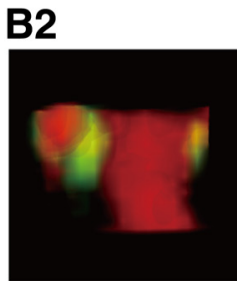

C2

D2
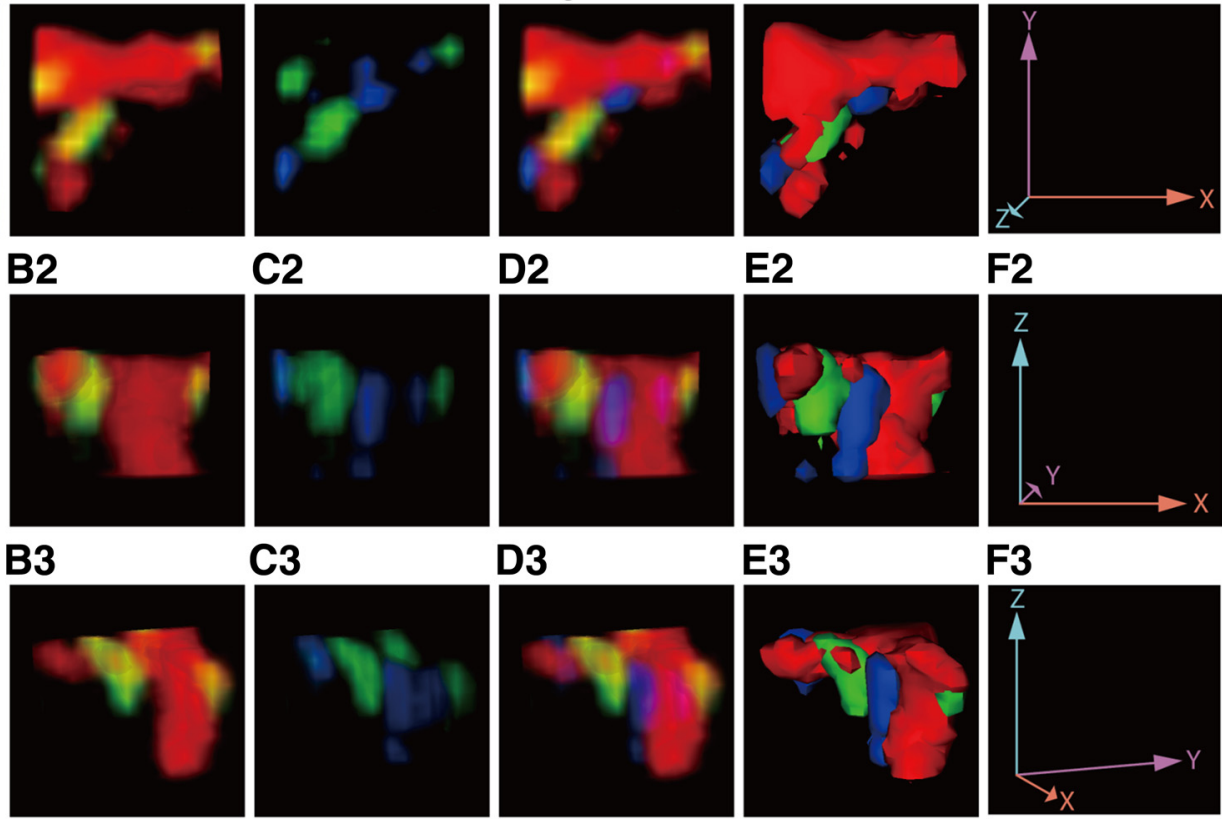

C3

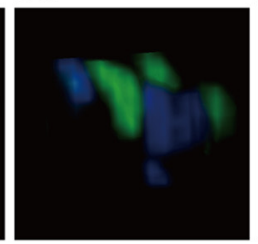

D3

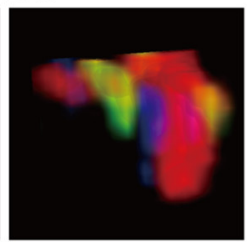

E2

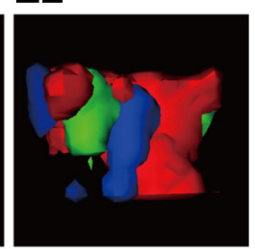

F2

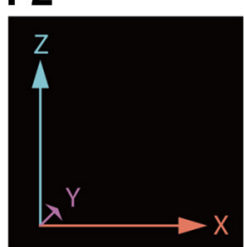

E3

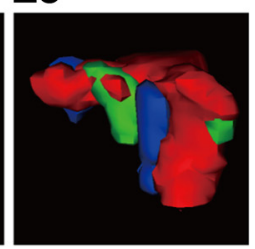

F3

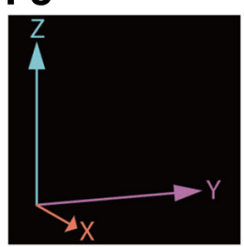

Figure 5. High-resolution $3 \mathrm{D}$ reconstruction of confocal imaging of a single contact between an ipRGC axon collateral and a DAC. $A$, Cropped image from Figure $4 F$ used to indicate the location and orientation of the synaptic site between an ipRGC axon collateral and a DAC dendrite. $\boldsymbol{B}-\boldsymbol{D}$, Volume rendered $3 \mathrm{D}$ image from a 29 stack confocal image with a $0.08 \mu \mathrm{m}$ interval. Colocalization (yellow) of a TH ${ }^{+}$DAC process (red) and PSD-95 (green) is observed in three orthogonal angles (B1-B3) while synaptophysin (blue) is in contact with PSD-95 (C1-C3). Synaptophysin puncta were not within the DAC dendrite (D1-D3). E, 3D rendering of the image with an opaque isosurface view from three different angles (E1-E3) clearly shows that PSD-95 and synaptophysin puncta are in direct contact. $\boldsymbol{F}$, Representation of the three orthogonal views with $X, Y$, and $Z$ axes (F1-F3) as orientation markers.

A

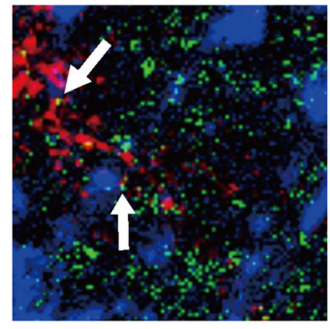

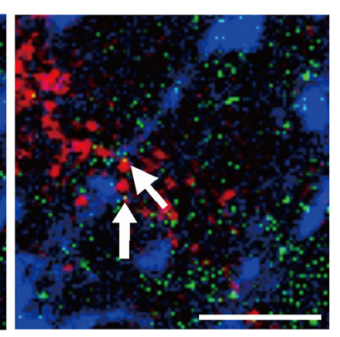

B

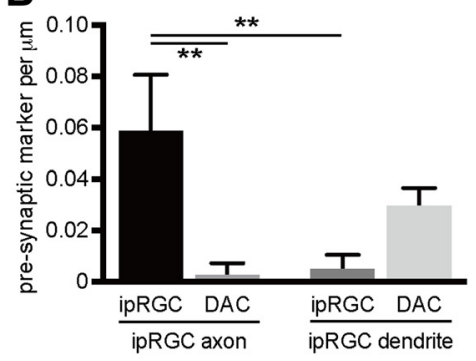

Figure 6. An ipRGC axon collateral colocalized with the presynaptic marker bassoon makes contact with TH-positive DAC processes. $A$, Confocal images taken in 2 separate $1 \mu \mathrm{m}$ optical sections within the same $z$-stack from a whole-mount retina in which DAC processes are marked by TH (blue), presynaptic active zones are labeled by bassoon (green), and an ipRGC axon collateral is labeled by alkaline phosphatase (red). Arrows indicate the colocalization of the presynaptic marker and the ipRGC axon collateral in direct apposition to DAC dendrites. Scale bar, $5 \mu \mathrm{m}$. B, Average number and cellular localization of bassoon-positive puncta at sites of contact between ipRGC axon collaterals and DACs (left bars) and ipRGC dendrites and DACs (right bars). ${ }^{* *} p<$ 0.01 , Tukey's test $(n=3)$.

peak current amplitude of $41.26 \mathrm{pA}$ and miniature EPSCs (Fig. $7 C$, left). Application of $100 \mu \mathrm{M} \mathrm{Cd}^{2+}$ suppressed the lightinduced inward current by $86.4 \%$ (5.62 pA; Fig. $7 C$, center). The effect of $\mathrm{Cd}^{2+}$ was partially reversible upon washout (Fig. 7C, right). Average data demonstrate that $\mathrm{Cd}^{2+}$ reduced ipRGCdriven inward current by $79.4 \%$ (Fig. $7 D ; n=9 ; p \leq 0.01$, Wilcoxon signed-rank test).

To determine whether $\mathrm{Cd}^{2+}$ suppresses ipRGC signaling to DACs by reducing the intrinsic ipRGC light response, we performed whole-cell current-clamp recordings of M1 ipRGCs in the presence of $50 \mu \mathrm{M} \mathrm{L}$-AP4 (Fig. 7E, left). $100 \mu \mathrm{M} \mathrm{Cd}^{2+}$ did not alter the amplitude of the light-evoked depolarization, but increased the depolarization time course (Fig. 7E, right). The number of light-evoked APs was slightly increased rather than decreased in the presence of $\mathrm{Cd}^{2+}$ (Fig. $7 E)$. Similar results were observed in two other cells. The results suggested that the observed effect of $\mathrm{Cd}^{2+}$ on DACs did not result from the inhibition of intrinsic photosensitivity of the ipRGCs. To determine whether $\mathrm{Cd}^{2+}$ acted postsynaptically on DACs, we assessed its effect on the DAC postsynaptic glutamate response in the presence of a mixture of synaptic blockers (50 $\mu \mathrm{M} \mathrm{L-AP4,} 20 \mu \mathrm{M}$ GABAzine, and $1 \mu \mathrm{M}$ strychnine). Application of 100 $\mu \mathrm{M}$ kainate, a nondesensitizing AMPAtype glutamate receptor agonist, induced a strong inward current in DACs; coapplication of $100 \mu \mathrm{M} \mathrm{Cd}{ }^{2+}$ during the kainate-induced response did not reduce the amplitude of the inward current in any cell tested (data not shown; $n=3$ ). These data suggested that $\mathrm{Cd}^{2+}$ did not act postsynaptically on DACs.

In summary, these experiments indicated that retrograde signal transmission from ipRGC axon collaterals was mediated by VGCCs located in axon collateral terminals. We next sought to distinguish the types of presynaptic VGCCs involved.

\section{N-type VGCCs significantly contribute to presynaptic signal transmission}

VGCCs are classified into two major categories according to their threshold for activation by depolarization: high- and low-voltageactivated channels. High-voltage-activated channels can be further subdivided into L-, N-, P/Q-, and R-type channels, whereas low- 

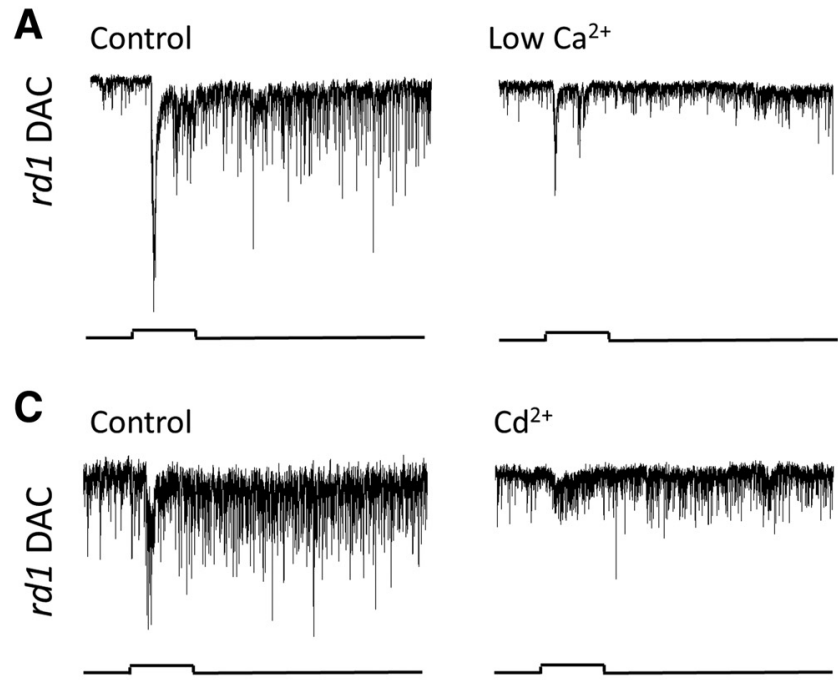

E

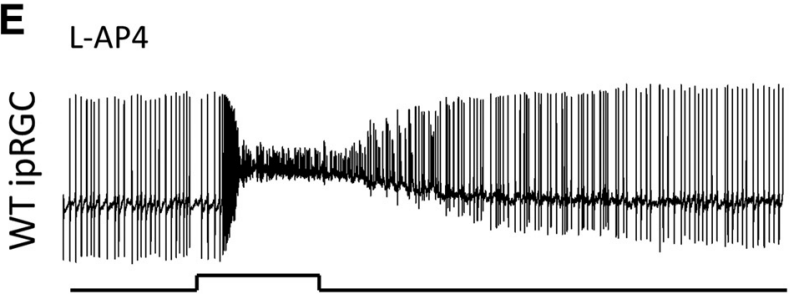

Wash

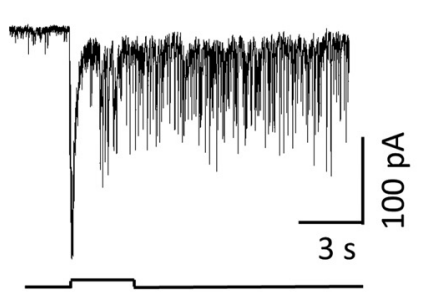

Wash

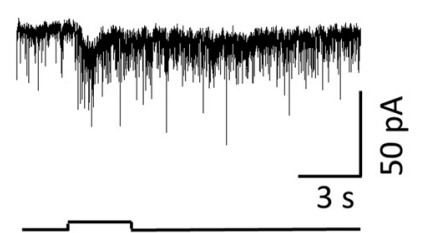

$\mathrm{L}-\mathrm{AP} 4+\mathrm{Cd}^{2+}$
B

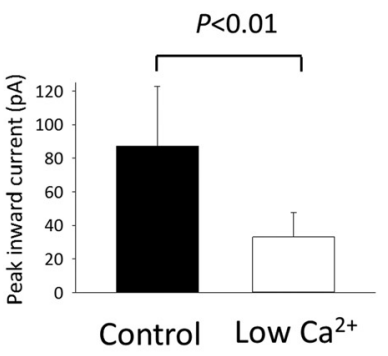

D

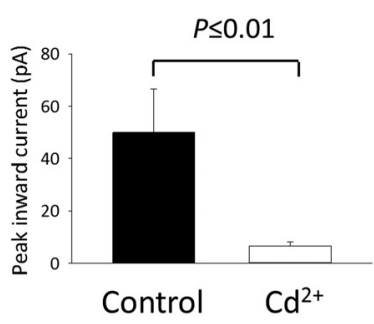

Figure 7. Signal transmission from ipRGCs to DACs is mediated by calcium channels. A, An ipRGC-driven $r d 1$ DAC light response in control extracellular media $\left(2 \mathrm{~mm} C \mathrm{C}^{2+}\right.$; left) was greatly reduced when switched to a low $\mathrm{Ca}^{2+}(0.5 \mathrm{~mm})$ extracellular media (center). The response completely recovered when switched back to the control extracellular $\mathrm{Ca}^{2+}$ condition (right). $\boldsymbol{B}$, Average data show that low $\mathrm{Ca}^{2+}$ significantly reduced the amplitude of the DAC inward current (Wilcoxon signed-rank test; $n=8$ ). $C$, An rd1 DAC light response (left) was severely attenuated by the application of $\mathrm{Cd}^{2+}\left(100 \mu \mathrm{m}\right.$; center). Washout partially restored the response (right). $\boldsymbol{D}$, Average data show that $\mathrm{Cd}^{2+}$ significantly reduced retrograde signal transmission (Wilcoxon signed-rank test; $\left.n=9\right)$. Average data are represented as mean \pm SEM. E, Current-clamp recording from a GFP-labeled M1 ipRGC showing that $100 \mu \mathrm{m} \mathrm{Cd}^{2+}$ prolonged the plateau phase of the light-induced membrane depolarization and slightly increased the number of light-induced APs. Left trace: control; right trace: $\left(\mathrm{d}^{2+}\right.$. Stimulation bar shows timing of light pulse $\left(3 \mathrm{~s} ; 470 \mathrm{~nm} ; 4.7 \times 10^{13} \mathrm{photons} \mathrm{cm}^{-2} \mathrm{~s}^{-1}\right)$.

voltage-activated channels only comprise T-type channels (Benarroch, 2010). The calcium channels that mediate $\mathrm{Ca}^{2+}$ influx in ipRGC axons seem to be distinct from those expressed in ipRGC dendrites and somas. Although light-induced $\mathrm{Ca}^{2+}$ influx in isolated ipRGCs is mediated primarily by somatic L-type VGCCs (Hartwick et al., 2007), this type of channel does not appear to mediate glutamate release from retinohypothalamic tract terminals through which ipRGCs send ambient illumination signals to neural targets in the brain; instead, neurotransmitter release from ipRGC axon terminals is mediated by $\mathrm{N}$-, P/Q-, R-, and T-type VGCCs (Mintz et al., 1995; Moldavan et al., 2006).

To determine the relative contribution of each subtype of VGCC (L-, N-, P/Q-, R-, and T-types) to retrograde synaptic transmission, we used specific antagonists of each channel subtype. These antagonists do not exert postsynaptic effects on glutamatergic responses; therefore, any effect observed was anticipated to be presynaptic (Luebke et al., 1993; Mintz et al., 1995). Of all the VGCC antagonists used, only the N-type blocker $\omega$-conotoxin GVIA significantly reduced the ipRGC-mediated light-induced inward current of DACs (Fig. 8A). Pooled data from $\mathrm{rd}$ and $\mathrm{Cnga3}^{-1-}$ retinas demonstrate that $\mathrm{N}$-type calcium channel blockade reduced the DAC inward current by an average of $47 \%$ (Fig. $8 A, n=7 ; p<0.05$, Wilcoxon signed-rank test). In contrast, other known $\mathrm{Ca}^{2+}$ channel blockers did not affect ipRGC-driven responses of DACs (Fig. $8 B-E$ ). To reveal whether an interaction existed between the VGCCs that could account for the residual current blocked by $\mathrm{Cd}^{2+}$ but not by conotoxin, we used a mixture of all of the VGCC antagonists and retested the ipRGC-mediated DAC light response. The VGCC blocker mixture contained the following: $\omega$-conotoxin GVIA (1 $\mu \mathrm{M})$, nifedipine $(10 \mu \mathrm{M}), \omega$-agatoxin IVA (100 nM), SNX 482 (150 nM), and mibefradil dihydrochloride (10 $\mu \mathrm{M})$. On average, the VGCC blocker mixture reduced the peak inward current of ipRGC-driven DAC light responses in $r d 1$ and $\mathrm{Cnga3}^{-1-}$ retinas by $46.1 \%$ (Fig. $8 F, n=6$; $p<0.05$, paired $t$ test). The inhibitory effects of the VGCC blocker mixture and conotoxin did not differ statistically ( $46.1 \%$ vs $47 \%$, respectively; $p=0.939, t$ test). These data suggested that the effect of the VGCC blocker mixture was entirely the result of inhibition of $\mathrm{N}$-type channels by conotoxin.

\section{ipRGCs are involved in light adaptation}

Because ipRGCs provide photic input to DACs and dopaminergic modulation of the cone pathway is associated with light adaptation (Jackson et al., 2012), we next sought to determine whether the ipRGC circuit is involved in light adaptation. We measured the light-adapted ERG response every 2 min continuously for $20 \mathrm{~min}$ to assess light-adapted visual function. To exclude an effect of circadian modulation on retinal function, all ERG recordings were performed on the first day of constant darkness (DD) at CT 6. Similar to previous studies (Jackson et al., 2012; Nagaya et al., 2015), in wild-type mice, the b-wave amplitude of the light-adapted ERG gradually increased with time and, after $6 \mathrm{~min}$, was significantly greater than the initiation time point (Fig. 9A, top traces, $B$ ). However, $M 1$ ipRGC elimination mice $\left(O p n 4^{D T A /+}\right)$, in which cell loss was confirmed with an antibody against melanopsin (Fig. 9F, G; M1 cells in Opn $4^{\text {DTA/+ }}=54 \pm 9$, control $=479 \pm 13$ per retina, $n=3, p<0.01$, $t$ test), exhibited an unchanged b-wave amplitude even after 20 min of light adaptation 
A

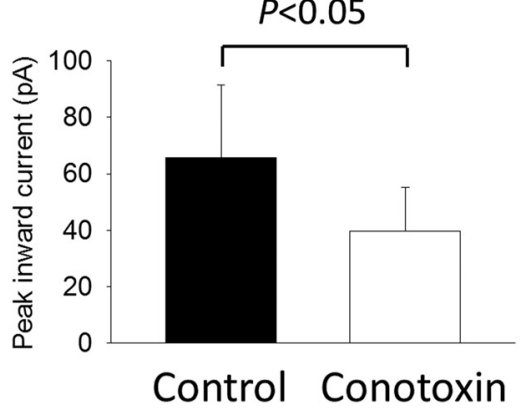

D

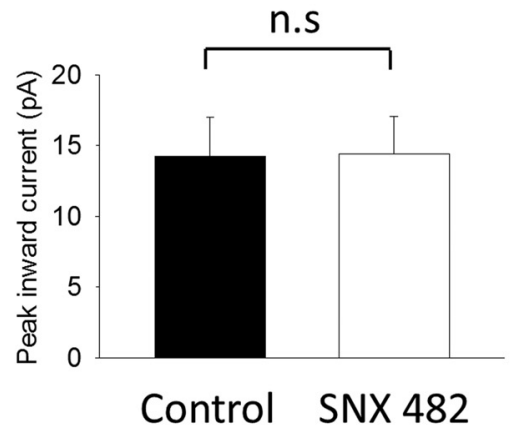

B

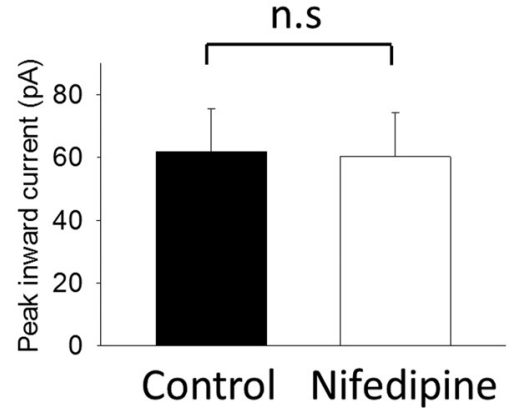

E

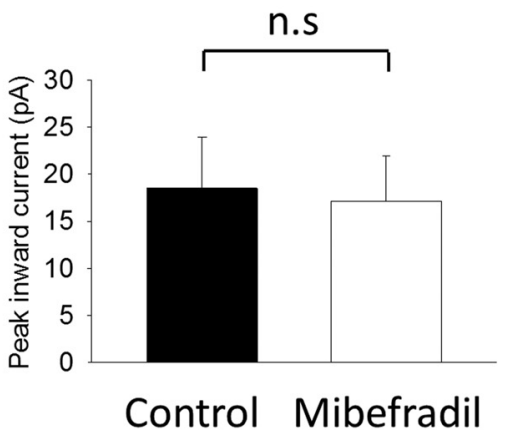

C

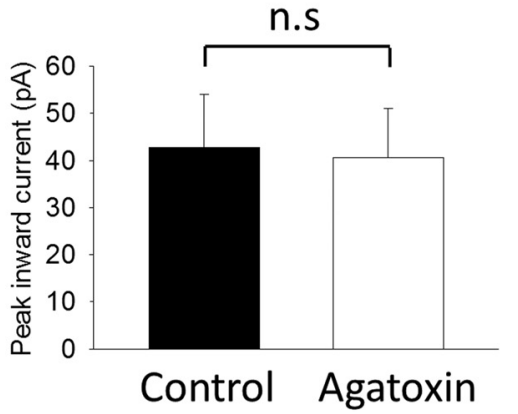

$\mathbf{F}$

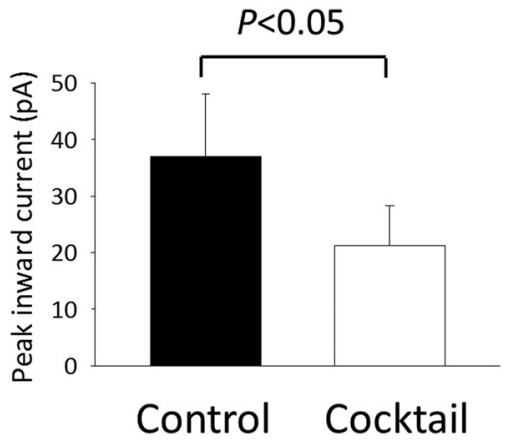

Figure 8. N-type voltage-gated calcium channels contribute to retrograde signal transmission. $\boldsymbol{A}$, The N-type VGCC blocker $\omega$-conotoxin GVIA (1 $\mu$ M) significantly suppressed the light-induced inward currents of $r d 1$ and cnga $3^{-1-}$ DACs (Wilcoxon signed-rank test; $\left.n=7\right)$. None of the other antagonists (B: $10 \mu m$ nifedipine (L-type), $n=5 ; \boldsymbol{C}: 100 \mathrm{~nm} \omega$-agatoxin IVA (P/Q-type), $n=3$; D: $150 \mathrm{~nm}$ SNX 482 (R-type), $n=3$; and $\boldsymbol{E}$ : $10 \mu \mathrm{m}$ mibefradil (T-type), $n=3$ ) significantly reduced signal transmission. $\boldsymbol{F}$, VGCC blocker mixture containing all of the antagonists ( $1 \mu \mathrm{m}$ conotoxin; $10 \mu$ m nifedipine; $100 \mathrm{~nm}$ agatoxin; $150 \mathrm{~nm}$ SNX 482, and $10 \mu$ m mibefradil) significantly reduced $r d 1$ and $c n g a 3^{-} /-$DAC light-induced responses (paired $t$ test; $n=6$ ). Bar charts are average data represented as the mean \pm SEM before and during drug application.

(Fig. $9 A$, traces in second row, $D$ ). Furthermore, we repeated the experiment using Opn $4^{\mathrm{Cre} /+} ; B r n 3 b^{Z d t a /+}$ mice in which most ipRGCs are eliminated, except for M1s that innervate the suprachiasmatic nucleus and intergeniculate leaflet (Chen et al., 2011). In these mice, we observed light-adapted b-wave facilitation that was similar to control (Fig. 9A, traces in third row, C), suggesting that M1 ipRGCs are sufficient to facilitate light adaptation.

To confirm that the light adaptation phenotype that we observed in Opn $4^{D T A /+}$ mice was due to a modulatory effect on the dopaminergic system, we intraperitoneally injected PD168077, a D4 receptor agonist, immediately before the ERG recording. This agonist has been shown to restore the light-adapted b-wave amplitude of mice that lack dopamine in the retina at CT 6 (Jackson et al., 2012). Furthermore, injection of PD168077 alone did not further increase the amplitude of light-adapted $b$-waves in wildtype mice (two-way ANOVA; Fig. 9A, bottom traces, $B$ ). After injection of PD168077, light-adapted b-wave amplitude was restored in mice lacking M1 ipRGCs (Fig. 9A, traces in fourth row, $D, E)$. The kinetics of b-wave potentiation in the Opn $4^{D T A /+}$ mice injected with PD168077 were slower than in the wild-type mice. This could have been a result of the gradual entry of PD168077 from the intraperitoneal injection site into the retina. Together, these results demonstrate that retrograde signaling from ipRGCs is involved in light adaptation through modulation of the dopaminergic system, which facilitates the cone pathway.

\section{Discussion}

In this study, we demonstrated that ipRGCs make anatomical and physiological connections through their axon collaterals with DACs, forming a centrifugal pathway in the retina. We further demonstrated that genetic ablation of M1 ipRGCs impaired the light-adapted ERG in mice and that the impairment could be restored by a dopamine receptor agonist. The results strongly suggest that M1 ipRGCs are necessary and sufficient to influence light adaptation through the centrifugal dopaminergic system. Our findings illustrate a functional role for ipRGCs in vision and elucidate the precise synaptic and circuit mechanisms underlying ipRGC-mediated visual functions.

\section{Route of retrograde signal transmission in the retina}

Our data demonstrate that the origin of retrograde signaling appears to be axon collateral-bearing M1 ipRGCs that comprise $\sim 10 \%$ of all M1 ipRGCs (Joo et al., 2013) and that retrograde signaling from ipRGCs to DACs is likely routed through intraretinal axon collaterals. Although axon collaterals have been reported in a small population of RGCs for decades, it was only recently demonstrated that they are an apparent specialization of ipRGCs (Dacey, 1985; Joo et al., 2013). The axon collateral branches from the ipRGC's primary axon before it exits the retina and projects back to the IPL (Joo et al., 2013). Our data clearly illustrated that the terminals of M1 ipRGC axon collaterals were colocalized with DAC processes in the outermost IPL, providing a possible site of synaptic contact between these two classes of neurons. We observed that the axon collateral terminals contained the synaptic vesicle protein synaptophysin, which was in direct apposition to the postsynaptic components revealed by PSD-95 on DAC dendrites. The significantly higher presynaptic contact between ipRGC axons and DACs than ipRGC dendrites to DACs indicates that our observation was not due to stochastic events. These data strongly suggest that ipRGC axon collaterals could form axodendritic synapses with DACs. Although the synaptic ultrastructure should be further examined with electron microscopy (Pickard and Sollars, 2010), our study is the first to 
A
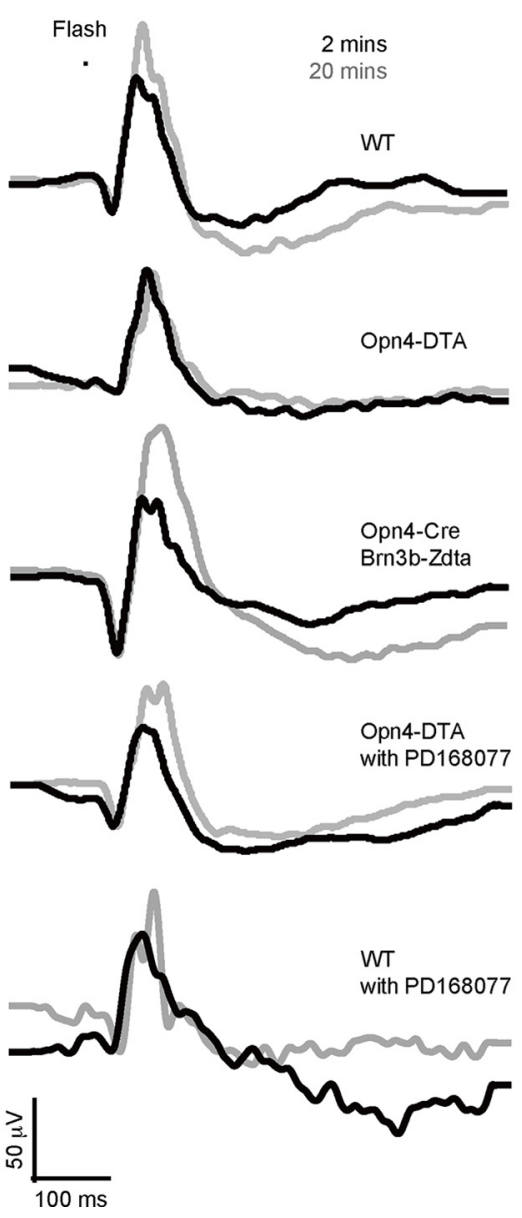
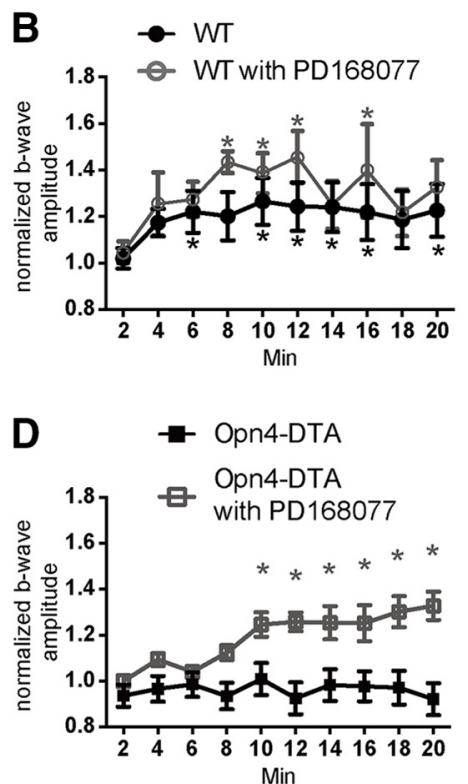

$\mathbf{F}$

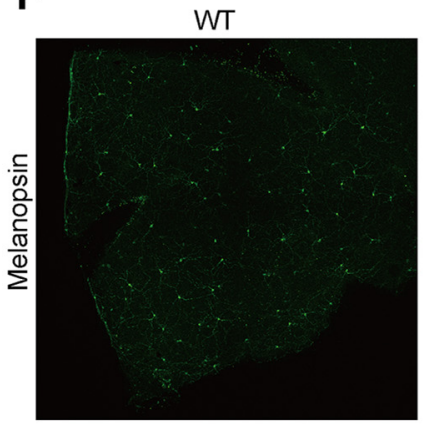

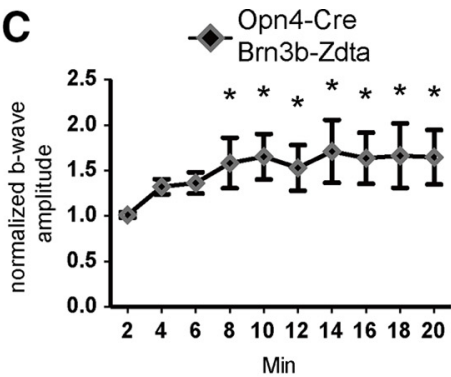

E

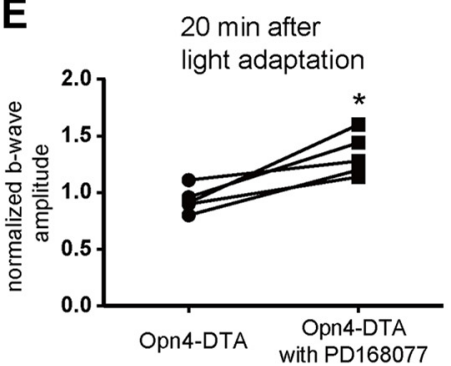

G

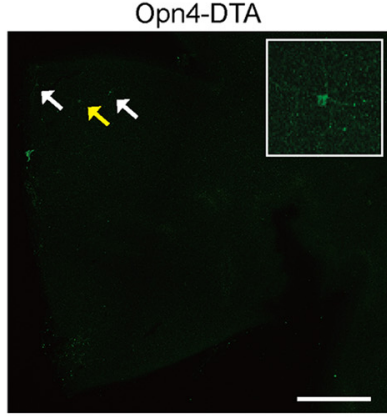

Figure 9. M1 ipRGCs modulate the light-adapted ERG b-wave via D4 dopamine receptors. $\boldsymbol{A}$, Representative light-adapted ERG recording traces after 2 min (black) or 20 min (gray) of light adaptation in wild-type, Opn $4^{\text {DTA/+ }}$ Opn $4^{\mathrm{Cre} /+}, \mathrm{Brn} 3 \mathrm{~b}^{\text {Zdta/+}}$, and PD168077-injected Opn4 ${ }^{\text {DTA/+ }}$, and wild-type mice (from top to bottom). $\boldsymbol{B}$, Light-adapted ERG b-wave amplitude plotted against light adaptation time in wild-type mice (closed circle, $n=8$ ). Most of the b-wave amplitudes were significantly higher after 6 min of light adaptation than they were after the first 2 min; the injection of PD168077 produced similar light adapted b-wave amplitudes as control (open circle, $n=5$ ). C, Similar to wild-type, in Opn4-Cre;Brn3b-Zdta mice, all of the b-wave amplitudes were significantly higher after $8 \mathrm{~min}$ of light adaptation than they were after the first $2 \mathrm{~min}(n=7)$. D, B-wave amplitudes from 0pn4-DTA mice remained unchanged throughout 20 min of light adaptation (closed square, $n=8$ ). Ten minuts after intraperitoneal PD168077 injection, the light-adapted ERG b-wave amplitudes were significantly higher than the initial time point from 0pn4-DTA mice (open square, $n=5$ ). $\boldsymbol{E}$, Paired plot of light-adapted ERG b-wave amplitudes from individual Opn4-DTA mice before and after PD168077 injection after 20 min of light adaptation. $\boldsymbol{F}$, Whole-mount immunofluorescence staining with a melanopsin antibody shows a dramatic reduction in the total number of melanopsin-immunopositive ipRGCs in 0pn4DTA mice (right) compared with wild-type (left). Only a few weakly stained M1 ipRGCs (arrows), characterized by dendritic stratification in the S1 layer of the IPL, remained in the 0pn4-DTA retina (right); an insert (right) displays a magnified image of one such cell (yellow arrow). G, Quantification of melanopsin-immunopositive ipRGCs from WT and Opn4-DTA mice ( $t$ test, $n=3$ ). For $\boldsymbol{B}-\boldsymbol{D}$, post hoc Bonferroni's test compared with 2 min bin. For $\boldsymbol{E}$, paired $t$ test, $n=5$. ${ }^{*} p<0.05$; ${ }^{* *} p<0.01$.

suggest that RGC axon collaterals are presynaptic to upstream orders of retinal neurons.

Our physiological data directly support the anatomical evidence for the retrograde neural pathway in the retina. Axons are presumed to use APs to transmit synaptic signals. Lightinduced responses of ipRGCs have two components: a graded potential and APs (Berson et al., 2002). In the presence of TTX, ipRGC APs were blocked but their graded potentials persisted. In this condition, the light-induced excitatory inward currents of DACs were undetectable, indicating that the graded potentials of ipRGCs did not generate excitatory currents in DACs. Therefore, we concluded that TTX-sensitive APs, not TTX-insensitive graded potentials of ipRGCs, mediate retrograde signal transmission. The conclusion derived from our patch-clamp results obtained from isolated retinas was further validated by our in vivo data: ocular TTX injection nearly eliminated ipRGC-driven c-Fos expression in DACs, suggesting that signal transmission from ipRGCs to DA neurons is mediated by APs in vivo.

Although our data suggest that APs generated in the ipRGC soma likely propagate along axon collaterals to mediate retrograde synaptic transmission to DACs, we cannot completely rule out other possibilities. First, TTX-sensitive APs initiated in the axon hillock could back-propagate into the dendritic arbors of ipRGCs, as observed in cortical pyramidal neurons (Stuart and Sakmann, 1994), and mediate synaptic transmission via dendrodendritic synapses with DACs. Second, both dendrites and axons of ipRGCs express melanopsin and are endogenously photosensitive (Berson et al., 2002; Hattar et al., 2002). Melanopsin-based membrane depolarization in either of these processes could trigger glutamate release locally onto DACs. Although evidence is needed, these possibilities exist because RGC dendrites contain synaptic vesicles and AMPA receptors of DACs are located in close proximity to melanopsin-immunopositive dendrites of 
ipRGCs (Sakai et al., 1986; Zhang et al., 2012). Last, ipRGCs could signal to DACs polysynaptically through multiple interneurons, although our data ruled out the involvement of ipRGC-coupled spiking amacrine cells (Reifler et al., 2015).

\section{Calcium dependence of presynaptic signal transmission}

Our results reveal that signal transmission from ipRGCs to DACs is calcium dependent because low extracellular calcium significantly reduced the amplitude of the light-induced inward currents of DACs. We postulate that APs generated in an ipRGC propagate along its axon collateral and depolarize its terminal. This depolarization results in the opening of VGCCs, enabling an influx of $\mathrm{Ca}^{2+}$ into the terminal. The global $\mathrm{Ca}^{2+}$ channel blocker $\mathrm{Cd}^{2+}$ almost completely blocked the light-induced inward currents of DACs. This blockage cannot be attributed to a postsynaptic effect because $\mathrm{Cd}^{2+}$ did not affect the AMPAreceptor-mediated inward current of DACs. Our results further reveal that presynaptic $\mathrm{Ca}^{2+}$ influx was partially mediated by N-type VGCCs. It is generally thought that N-type VGCCs are expressed in axon terminals and are responsible for triggering neurotransmitter release (Benarroch, 2010), although some studies showed that they are also expressed on dendrites (Mills et al., 1994; Kisilevsky et al., 2008). Indeed, N-, P/Q-, R-, and T-type channels are involved in synaptic transmission from ipRGCs to neurons in the suprachiasmatic nucleus, suggesting that ipRGC axons use these channels for neurotransmitter release (Moldavan et al., 2006). However, we observed that P/Q-, R-, and T-type channels had no detectable involvement in signal transmission from ipRGCs to DACs. This difference suggests that ipRGC axon collaterals may not express these subtypes of VGCCs or that they possess these channels, but they are not involved in synaptic transmission. In addition, L-type VGCCs, which are generally expressed in the somas and dendrites of neurons (Hell et al., 1993; Simon et al., 2003), do not appear to mediate synaptic transmission to DACs, further suggesting that ipRGC dendrites are unlikely the conduit for signal transmission. Instead, the data further support a model in which AP-driven retrograde signal transmission partially via conotoxin-sensitive N-type VGCCs, is routed through ipRGC axon collaterals. However, the conotoxin-resistant transmission that we observed could reflect synaptic release triggered by other sources of calcium such as the endoplasmic reticulum.

\section{Potential role for intraretinal retrograde signaling in light adaptation}

Our results further demonstrated that retrograde signaling from M1 ipRGCs to DACs is necessary and sufficient to influence light adaptation by showing a deficit in the photopic ERG b-wave during light adaptation in M1 ipRGC elimination mice, but not in non-M1 ipRGC elimination mice. Although the mechanisms responsible for b-wave light adaptation remain to be determined fully, cone photoreceptor responses and synaptic plasticity between cones and bipolar cells are likely to play critical roles in the gradual increase of the photopic b-wave during light adaptation (Gouras and MacKay, 1989; Bui and Fortune, 2006; Nagaya et al., 2015). However, facilitation of the photopic b-wave is impaired in retina-specific dopamine depletion mice, suggesting that cones and bipolar cells may modulate the light-adapted b-wave, at least in part via the dopaminergic system (Jackson et al., 2012). Cones can drive DACs directly through ectopic ON bipolar cell synapses in the OFF IPL (route 4 in Fig. 10A), which may contribute to $\mathrm{b}$-wave light adaptation through increased levels of retinal dopamine (Zhang et al., 2007; Dumitrescu et al., 2009; Hoshi et al.,

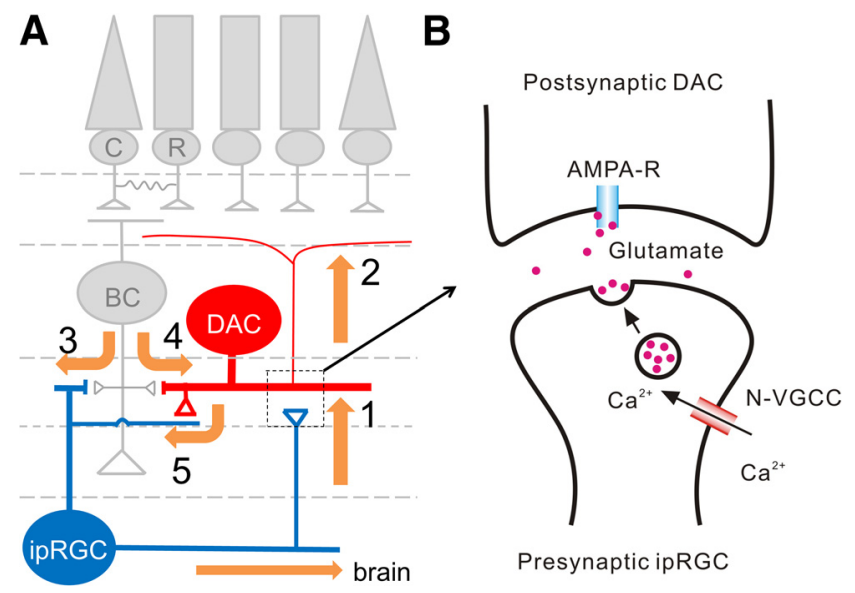

Figure 10. Proposed neural pathways and synaptic mechanisms underlying ipRGC influence on light adaptation. $A$, It is proposed that ipRGCs signal to DACs via their axon collaterals to convey melanopsin-based signals (route 1) from the inner to outer retina (route 2). Rods and cones may use this retrograde signaling pathway as an alternative route to send feedback signals through ipRGCs, back to the outer retina (route 3); this route likely complements the primary feedback pathway in which rod and cone signals are transmitted back to the outer retina via DACs (route 4). Retrograde information transfer from ipRGCs to DACs is reciprocated by a feedback projection from DACs (route 5). Through this projection, rod and cone signals are indirectly relayed to ipRGCs via DACs. $\boldsymbol{B}$, Activation of the ipRGC axon collateral triggers $\mathrm{Ca}^{2+}$ influx partially via N-type VGCCs into the collateral terminals, resulting in glutamate release onto postsynaptic DACs. Glutamate excites DACs through activation of AMPA-type glutamate receptors, which depolarizes DACs and increases their AP firing frequency, triggering dopamine release.

2009; Newkirk et al., 2013). Cones may also excite DACs through ipRGCs retrogradely (Zhang et al., 2008; Atkinson et al., 2013; Newkirk et al., 2013) because they can activate ipRGCs through ectopic ON bipolar cell synapses in the OFF IPL (Dumitrescu et al., 2009; Hoshi et al., 2009; route 3 in Fig. 10A). The latter provides an alternative route for cone and bipolar cell contribution to the photopic b-wave through the ipRGC circuit and dopaminergic system. This route may partially explain why an impaired photopic b-wave was observed in ipRGC elimination mice.

The impaired photopic b-wave in ipRGC elimination mice could also be the result of a loss of ipRGC network and photoreceptor adaptation. Like conventional RGCs, ipRGCs undergo network adaptation because they receive excitatory input from bipolar cells (Wong et al., 2007; route 3 in Fig. 10A) as well as inhibitory inputs (GABA, glycine, and dopamine) from amacrine cells, including DACs (route 5 in Fig. 10A; Belenky et al., 2003; Viney et al., 2007; Vugler et al., 2007; Wong et al., 2007; Van Hook et al., 2012). Unlike regular RGCs, ipRGCs possess the photopigment melanopsin, which can produce a sustained light signal under steady illumination (Wong et al., 2005; Wong, 2012; Do and Yau, 2013). Therefore, ipRGCs can integrate lightadapted cone and melanopsin signals and in turn transmit these signals through their axon collaterals to DACs retrogradely (route 1 in Fig. 10A), triggering dopamine release (DkhissiBenyahya et al., 2013; Fig. 10B). Increased dopamine release mediated by ipRGC activity can also act through D4 dopamine receptors expressed on cones, where they are known to affect cGMP metabolism, gene expression, and rod-cone coupling to regulate cone photoreceptor adaptation (Jackson et al., 2011; route 2 in Fig. 10A); this was demonstrated through the restoration of the impaired b-wave with a $\mathrm{D} 4$ receptor agonist in ipRGC elimination mice (Fig. 9).

Although cones could signal to DACs through bipolar cells in M1 ipRGC elimination mice (route 4 in Fig. 10A), we failed to 
detect any light-adapted b-wave using the highest light intensity of our ERG system (Fig. 9D). It appears that cones may require higher intensities to mediate light adaptation in the absence of M1 ipRGCs. Indeed, higher flash intensities can produce greater light-adapted b-wave facilitation than the intensity that we used here (Jackson et al., 2012). It is worth nothing that the impaired light-adapted b-wave that we observed without M1 ipRGCs is contradictory to the previous report showing that selective depletion of wavelengths to which melanopsin is most sensitive enhanced light adaptation (Allen et al., 2014). Future investigations will need to determine whether reducing melanopsin signaling alone and eliminating the M1 ipRGC circuit may play different roles in light adaptation of the visual system.

\section{References}

Allen AE, Storchi R, Martial FP, Petersen RS, Montemurro MA, Brown TM, Lucas RJ (2014) Melanopsin-driven light adaptation in mouse vision. Curr Biol 24:2481-2490. CrossRef Medline

Atkinson CL, Feng J, Zhang DQ (2013) Functional integrity and modification of retinal dopaminergic neurons in the rd1 mutant mouse: roles of melanopsin and GABA. J Neurophysiol 109:1589-1599. CrossRef Medline

Belenky MA, Smeraski CA, Provencio I, Sollars PJ, Pickard GE (2003) Melanopsin retinal ganglion cells receive bipolar and amacrine cell synapses. J Comp Neurol 460:380-393. CrossRef Medline

Benarroch EE (2010) Neuronal voltage-gated calcium channels: brief overview of their function and clinical implications in neurology. Neurology 74:1310-1315. CrossRef Medline

Berson DM, Dunn FA, Takao M (2002) Phototransduction by retinal ganglion cells that set the circadian clock. Science 295:1070-1073. CrossRef Medline

Biel M, Seeliger M, Pfeifer A, Kohler K, Gerstner A, Ludwig A, Jaissle G, Fauser S, Zrenner E, Hofmann F (1999) Selective loss of cone function in mice lacking the cyclic nucleotide-gated channel CNG3. Proc Natl Acad Sci U S A 96:7553-7557. CrossRef Medline

Boynton RM, Whitten DN (1970) Visual adaptation in monkey cones: recordings of late receptor potentials. Science 170:1423-1426. CrossRef Medline

Bui BV, Fortune B (2006) Origin of electroretinogram amplitude growth during light adaptation in pigmented rats. Vis Neurosci 23:155-167. Medline

Bunting M, Bernstein KE, Greer JM, Capecchi MR, Thomas KR (1999) Targeting genes for self-excision in the germ line. Genes Dev 13:1524-1528. CrossRef Medline

Calvert PD, Krasnoperova NV, Lyubarsky AL, Isayama T, Nicoló M, Kosaras B, Wong G, Gannon KS, Margolskee RF, Sidman RL, Pugh EN Jr, Makino CL, Lem J (2000) Phototransduction in transgenic mice after targeted deletion of the rod transducin alpha-subunit. Proc Natl Acad Sci U S A 97:13913-13918. CrossRef Medline

Carter-Dawson LD, LaVail MM, Sidman RL (1978) Differential effect of the rd mutation on rods and cones in the mouse retina. Invest Ophthalmol Vis Sci 17:489-498. Medline

Chang B, Dacey MS, Hawes NL, Hitchcock PF, Milam AH, Atmaca-Sonmez P, Nusinowitz S, Heckenlively JR (2006) Cone photoreceptor function loss-3, a novel mouse model of achromatopsia due to a mutation in Gnat2. Invest Ophthalmol Vis Sci 47:5017-5021. CrossRef Medline

Chen SK, Badea TC, Hattar S (2011) Photoentrainment and pupillary light reflex are mediated by distinct populations of ipRGCs. Nature 476:92-95. CrossRef Medline

Dacey DM (1985) Wide-spreading terminal axons in the inner plexiform layer of the cat's retina: evidence for intrinsic axon collaterals of ganglion cells. J Comp Neurol 242:247-262. CrossRef Medline

Dacey DM (1988) Dopamine-accumulating retinal neurons revealed by in vitro fluorescence display a unique morphology. Science 240:1196-1198. CrossRef Medline

Dkhissi-Benyahya O, Coutanson C, Knoblauch K, Lahouaoui H, Leviel V, Rey C, Bennis M, Cooper HM (2013) The absence of melanopsin alters retinal clock function and dopamine regulation by light. Cell Mol Life Sci 70:3435-3447. CrossRef Medline

Do MT, Yau KW (2013) Adaptation to steady light by intrinsically photo- sensitive retinal ganglion cells. Proc Natl Acad Sci U S A 110:7470-7475. CrossRef Medline

Dowling JE, Ehinger B (1975) Synaptic organization of the aminecontaining interplexiform cells of the goldfish and Cebus monkey retinas. Science 188:270-273. CrossRef Medline

Dumitrescu ON, Pucci FG, Wong KY, Berson DM (2009) Ectopic retinal ON bipolar cell synapses in the OFF inner plexiform layer: contacts with dopaminergic amacrine cells and melanopsin ganglion cells. J Comp Neurol 517:226-244. CrossRef Medline

Dunn FA, Doan T, Sampath AP, Rieke F (2006) Controlling the gain of rod-mediated signals in the Mammalian retina. J Neurosci 26:3959-3970. CrossRef Medline

Ecker JL, Dumitrescu ON, Wong KY, Alam NM, Chen SK, LeGates T, Renna JM, Prusky GT, Berson DM, Hattar S (2010) Melanopsin-expressing retinal ganglion-cell photoreceptors: cellular diversity and role in pattern vision. Neuron 67:49-60. CrossRef Medline

Gouras P, MacKay CJ (1989) Growth in amplitude of the human cone electroretinogram with light adaptation. Invest Ophthalmol Vis Sci 30: 625-630. Medline

Green DG, Dowling JE, Siegel IM, Ripps H (1975) Retinal mechanisms of visual adaptation in the skate. J Gen Physiol 65:483-502. CrossRef Medline

Güler AD, Ecker JL, Lall GS, Haq S, Altimus CM, Liao HW, Barnard AR, Cahill H, Badea TC, Zhao H, Hankins MW, Berson DM, Lucas RJ, Yau KW, Hattar S (2008) Melanopsin cells are the principal conduits for rod-cone input to non-image-forming vision. Nature 453:102-105. CrossRef Medline

Hartwick AT, Bramley JR, Yu J, Stevens KT, Allen CN, Baldridge WH, Sollars PJ, Pickard GE (2007) Light-evoked calcium responses of isolated melanopsinexpressing retinal ganglion cells. J Neurosci 27:13468-13480. CrossRef Medline

Hattar S, Liao HW, Takao M, Berson DM, Yau KW (2002) Melanopsincontaining retinal ganglion cells: architecture, projections, and intrinsic photosensitivity. Science 295:1065-1070. CrossRef Medline

Hattar S, Lucas RJ, Mrosovsky N, Thompson S, Douglas RH, Hankins MW, Lem J, Biel M, Hofmann F, Foster RG, Yau KW (2003) Melanopsin and rod-cone photoreceptive systems account for all major accessory visual functions in mice. Nature 424:76-81. Medline

Hayashida Y, Ishida AT (2004) Dopamine receptor activation can reduce voltage-gated $\mathrm{Na}+$ current by modulating both entry into and recovery from inactivation. J Neurophysiol 92:3134-3141. CrossRef Medline

Hell JW, Westenbroek RE, Warner C, Ahlijanian MK, Prystay W, Gilbert MM, Snutch TP, Catterall WA (1993) Identification and differential subcellular localization of the neuronal class C and class D L-type calcium channel alpha 1 subunits. J Cell Biol 123:949-962. CrossRef Medline

Henny P, Jones BE (2006) Innervation of orexin/hypocretin neurons by GABAergic, glutamatergic or cholinergic basal forebrain terminals evidenced by immunostaining for presynaptic vesicular transporter and postsynaptic scaffolding proteins. J Comp Neurol 499:645-661. CrossRef Medline

Hoshi H, Liu WL, Massey SC, Mills SL (2009) ON inputs to the OFF layer: bipolar cells that break the stratification rules of the retina. J Neurosci 29:8875-8883. CrossRef Medline

Hunt SP, Pini A, Evan G (1987) Induction of c-fos-like protein in spinal cord neurons following sensory stimulation. Nature 328:632-634. CrossRef Medline

Ichinose T, Lukasiewicz PD (2007) Ambient light regulates sodium channel activity to dynamically control retinal signaling. J Neurosci 27:47564764. CrossRef Medline

Jackson CR, Chaurasia SS, Hwang CK, Iuvone PM (2011) Dopamine D(4) receptor activation controls circadian timing of the adenylyl cyclase 1/ cyclic AMP signaling system in mouse retina. Eur J Neurosci 34:57-64. CrossRef Medline

Jackson CR, Ruan GX, Aseem F, Abey J, Gamble K, Stanwood G, Palmiter RD, Iuvone PM, McMahon DG (2012) Retinal dopamine mediates multiple dimensions of light-adapted vision. J Neurosci 32:9359-9368. CrossRef Medline

Jékely G, Arendt D (2007) Cellular resolution expression profiling using confocal detection of NBT/BCIP precipitate by reflection microscopy. Biotechniques 42:751-755. CrossRef Medline

Joo HR, Peterson BB, Dacey DM, Hattar S, Chen SK (2013) Recurrent axon 
collaterals of intrinsically photosensitive retinal ganglion cells. Vis Neurosci 30:175-182. CrossRef Medline

Kisilevsky AE, Mulligan SJ, Altier C, Iftinca MC, Varela D, Tai C, Chen L, Hameed S, Hamid J, Macvicar BA, Zamponi GW (2008) D1 receptors physically interact with $\mathrm{N}$-type calcium channels to regulate channel distribution and dendritic calcium entry. Neuron 58:557-570. CrossRef Medline

Knapp AG, Dowling JE (1987) Dopamine enhances excitatory amino acidgated conductances in cultured retinal horizontal cells. Nature 325: 437-439. CrossRef Medline

Krizaj D, Gábriel R, Owen WG, Witkovsky P (1998) Dopamine D2 receptor-mediated modulation of rod-cone coupling in the Xenopus retina. J Comp Neurol 398:529-538. Medline

Lasater EM, Dowling JE (1985) Dopamine decreases conductance of the electrical junctions between cultured retinal horizontal cells. Proc Natl Acad Sci U S A 82:3025-3029. CrossRef Medline

Luebke JI, Dunlap K, Turner TJ (1993) Multiple calcium channel types control glutamatergic synaptic transmission in the hippocampus. Neuron 11:895-902. CrossRef Medline

Maxwell IH, Maxwell F, Glode LM (1986) Regulated expression of a diphtheria toxin A-chain gene transfected into human cells: possible strategy for inducing cancer cell suicide. Cancer Res 46:4660-4664. Medline

Mills LR, Niesen CE, So AP, Carlen PL, Spigelman I, Jones OT (1994) $\mathrm{N}$-type Ca2 + channels are located on somata, dendrites, and a subpopulation of dendritic spines on live hippocampal pyramidal neurons. J Neurosci 14:6815-6824. Medline

Mills SL, Massey SC (1995) Differential properties of two gap junctional pathways made by AII amacrine cells. Nature 377:734-737. CrossRef Medline

Mills SL, Xia XB, Hoshi H, Firth SI, Rice ME, Frishman LJ, Marshak DW (2007) Dopaminergic modulation of tracer coupling in a ganglionamacrine cell network. Vis Neurosci 24:593-608. Medline

Mintz IM, Sabatini BL, Regehr WG (1995) Calcium control of transmitter release at a cerebellar synapse. Neuron 15:675-688. CrossRef Medline

Moldavan MG, Irwin RP, Allen CN (2006) Presynaptic GABA(B) receptors regulate retinohypothalamic tract synaptic transmission by inhibiting voltage-gated Ca2+ channels. J Neurophysiol 95:3727-3741. CrossRef Medline

Müller LP, Do MT, Yau KW, He S, Baldridge WH (2010) Tracer coupling of intrinsically photosensitive retinal ganglion cells to amacrine cells in the mouse retina. J Comp Neurol 518:4813-4824. CrossRef Medline

Nagaya M, Ueno S, Kominami T, Nakanishi A, Koyasu T, Kondo M, Furukawa T, Terasaki H (2015) Pikachurin protein required for increase of cone electroretinogram B-wave during light adaptation. PLoS One 10: e0128921. CrossRef Medline

Nakatani K, Tamura T, Yau KW (1991) Light adaptation in retinal rods of the rabbit and two other nonprimate mammals. J Gen Physiol 97: 413-435. CrossRef Medline

Newkirk GS, Hoon M, Wong RO, Detwiler PB (2013) Inhibitory inputs tune the light response properties of dopaminergic amacrine cells in mouse retina. J Neurophysiol 110:536-552. CrossRef Medline

Panda S, Provencio I, Tu DC, Pires SS, Rollag MD, Castrucci AM, Pletcher MT, Sato TK, Wiltshire T, Andahazy M, Kay SA, Van Gelder RN, Hogenesch JB (2003) Melanopsin is required for non-image-forming photic responses in blind mice. Science 301:525-527. CrossRef Medline

Peterson BB, Dacey DM (1998) Morphology of human retinal ganglion cells with intraretinal axon collaterals. Vis Neurosci 15:377-387. Medline

Pickard GE, Sollars PJ (2010) Intrinsically photosensitive retinal ganglion cells. Sci China Life Sci 53:58-67. CrossRef Medline

Reifler AN, Chervenak AP, Dolikian ME, Benenati BA, Li BY, Wachter RD, Lynch AM, Demertzis ZD, Meyers BS, Abufarha FS, Jaeckel ER, Flannery
MP, Wong KY (2015) All spiking, sustained ON displaced amacrine cells receive gap-junction input from melanopsin ganglion cells. Curr Biol 25:2763-2773. CrossRef Medline

Sakai HM, Naka K, Dowling JE (1986) Ganglion cell dendrites are presynaptic in catfish retina. Nature 319:495-497. CrossRef Medline

Schmidt TM, Taniguchi K, Kofuji P (2008) Intrinsic and extrinsic light responses in melanopsin-expressing ganglion cells during mouse development. J Neurophysiol 100:371-384. CrossRef Medline

Simon M, Perrier JF, Hounsgaard J (2003) Subcellular distribution of L-type Ca2 + channels responsible for plateau potentials in motoneurons from the lumbar spinal cord of the turtle. Eur J Neurosci 18:258-266. CrossRef Medline

Slaughter MM, Miller RF (1981) 2-amino-4-phosphonobutyric acid: a new pharmacological tool for retina research. Science 211:182-185. CrossRef Medline

Stuart GJ, Sakmann B (1994) Active propagation of somatic action potentials into neocortical pyramidal cell dendrites. Nature 367:69-72. CrossRef Medline

Tu DC, Zhang D, Demas J, Slutsky EB, Provencio I, Holy TE, Van Gelder RN (2005) Physiologic diversity and development of intrinsically photosensitive retinal ganglion cells. Neuron 48:987-999. CrossRef Medline

Van Hook MJ, Wong KY, Berson DM (2012) Dopaminergic modulation of ganglion-cell photoreceptors in rat. Eur J Neurosci 35:507-518. CrossRef Medline

Viney TJ, Balint K, Hillier D, Siegert S, Boldogkoi Z, Enquist LW, Meister M, Cepko CL, Roska B (2007) Local retinal circuits of melanopsincontaining ganglion cells identified by transsynaptic viral tracing. Curr Biol 17:981-988. CrossRef Medline

Vugler AA, Redgrave P, Semo M, Lawrence J, Greenwood J, Coffey PJ (2007) Dopamine neurones form a discrete plexus with melanopsin cells in normal and degenerating retina. Exp Neurol 205:26-35. CrossRef Medline

Warren EJ, Allen CN, Brown RL, Robinson DW (2006) The light-activated signaling pathway in SCN-projecting rat retinal ganglion cells. Eur J Neurosci 23:2477-2487. CrossRef Medline

Witkovsky P (2004) Dopamine and retinal function. Doc Ophthalmol 108: 17-40. CrossRef Medline

Wong KY (2012) A retinal ganglion cell that can signal irradiance continuously for 10 hours. J Neurosci 32:11478-11485. CrossRef Medline

Wong KY, Dunn FA, Berson DM (2005) Photoreceptor adaptation in intrinsically photosensitive retinal ganglion cells. Neuron 48:1001-1010. CrossRef Medline

Wong KY, Dunn FA, Graham DM, Berson DM (2007) Synaptic influences on rat ganglion-cell photoreceptors. J Physiol 582:279-296. CrossRef Medline

Xue T, Do MT, Riccio A, Jiang Z, Hsieh J, Wang HC, Merbs SL, Welsbie DS, Yoshioka T, Weissgerber P, Stolz S, Flockerzi V, Freichel M, Simon MI, Clapham DE, Yau KW (2011) Melanopsin signalling in mammalian iris and retina. Nature 479:67-73. CrossRef Medline

Zhang DQ, Stone JF, Zhou T, Ohta H, McMahon DG (2004) Characterization of genetically labeled catecholamine neurons in the mouse retina. Neuroreport 15:1761-1765. CrossRef Medline

Zhang DQ, Zhou TR, McMahon DG (2007) Functional heterogeneity of retinal dopaminergic neurons underlying their multiple roles in vision. J Neurosci 27:692-699. CrossRef Medline

Zhang DQ, Wong KY, Sollars PJ, Berson DM, Pickard GE, McMahon DG (2008) Intraretinal signaling by ganglion cell photoreceptors to dopaminergic amacrine neurons. Proc Natl Acad Sci U S A 105:14181-14186. CrossRef Medline

Zhang DQ, Belenky MA, Sollars PJ, Pickard GE, McMahon DG (2012) Melanopsin mediates retrograde visual signaling in the retina. PLoS One 7:e42647. CrossRef Medline 